\title{
Misinterpretations in Palynology
}

Example 1: Tripartite Feature in

Gymnosperms - Impression Mark - 68

Example 2: Tripartite Feature in

Angiosperms - Triangular Tenuitas - 68

Example 3: Tripartite Feature in

Angiosperms - Synaperture - 68

Example 4: Tripartite Feature in

Angiosperms - Trichotomosulcus - 70

Example 5: Tripartite Feature in

Angiosperms - Sulci vs. Colpi vs.

Tenuitas - 70

Example 6: Tripartite Feature in

Angiosperms - Triradiate Aperture - 70

Example 7: Apertures in

Angiosperms - Planaperturate - 70

Example 8: Apertures in

Angiosperms - Inconspicuous Pori - 72

Example 9: Apertures in

Angiosperms - Inconspicuous Colpi - 72

Example 10: Apertures in

Angiosperms - Hidden Apertures - 73

Example 11: Apertures in

Angiosperms - Ring-like Apertures vs.

Colpate-Operculate - 73

Example 12: Apertures in

Angiosperms - Tenuitas vs. Poroid - 73
Example 13: Apertures in Angiosperms Infoldings vs. Apertures - 73

Example 14: Apertures in

Angiosperms - Ulcerate-Operculate vs. Ring-like Aperture - 74

Example 15: Apertures in Angiosperms Disulcate vs. Dicolpate - 74

Example 16: Apertures in Angiosperms - Zon-, Zono-, Zoni-, Zona- vs. Ring-like Aperture and Stephanoaperturate Pollen - 75

Example 17: Magnification Effect -

Retipilate vs. Reticulum Cristatum - 76

Example 18: Dispersal Units - Massula vs. Polyad - 76

Example 19: Preparation Effect — Psilate vs. Ornamented - 77

Example 20: Preparation Effect -

Areolate-Fossulate vs. Verrucate - 78

Example 21: Preparation Effect - Striate vs. Striato-Reticulate - 78

Example 22: Staining Methods -

Absence or Presence of Endexine - $\mathbf{8 0}$

References - 84 
T he description of pollen ornamentation depends on three major parameters (1) the interpretations of the palynologist (which are subjective), (2) the pollen terminology applied, and (3) the magnification, resolution, and methods used.

The application of different preparation and staining methods and a combined analysis with light microscopy, scanning- and transmission electron microscopy are essential for the interpretation of pollen characters. Investigation of recent and fossil pollen material often reveals interesting features that in some cases may be misinterpreted. To demonstrate the wide range of possible misinterpretations, the following examples are given:

\section{Example 1: Tripartite Feature in Gymnosperms - Impression Mark}

M ature pollen of conifers, such as Abies, Larix, and Pseudotsuga, often shows proximally a Y-shaped bulge on the proximal polar side, comparable to a tetrad mark, which is called an impression mark (Fig. 1; Harley 1999). The mark results from the close proximity of the four pollen grains at the post-meiotic tetrad phase and is retained afterwards and is not a germination feature. Impression marks are also found in palm pollen. Note: the term tetrad mark is restricted to spores, where it is a germination feature.

\section{Example 2: Tripartite Feature in Angiosperms - Triangular Tenuitas}

S uperficially similar features in angiosperms are not comparable to those observed in gymnosperms. In recent and fossil Sapindaceae a three-armed feature (more precisely a triangle) is found. Cardiospermum has a narrow triangular tenuitas (thinning) at the proximal pole, whereas other recent and subfossil Sapindaceae show such a feature at both poles (Fig. 2).

\section{Example 3: Tripartite Feature in Angiosperms - Synaperture}

7 iangular pollen as found in Myrtaceae, some Primulaceae (Primula farinosa or P. denticulata) and Loranthaceae is characterized by a tripartite feature in both polar areas (Fig. 3). These are in fact
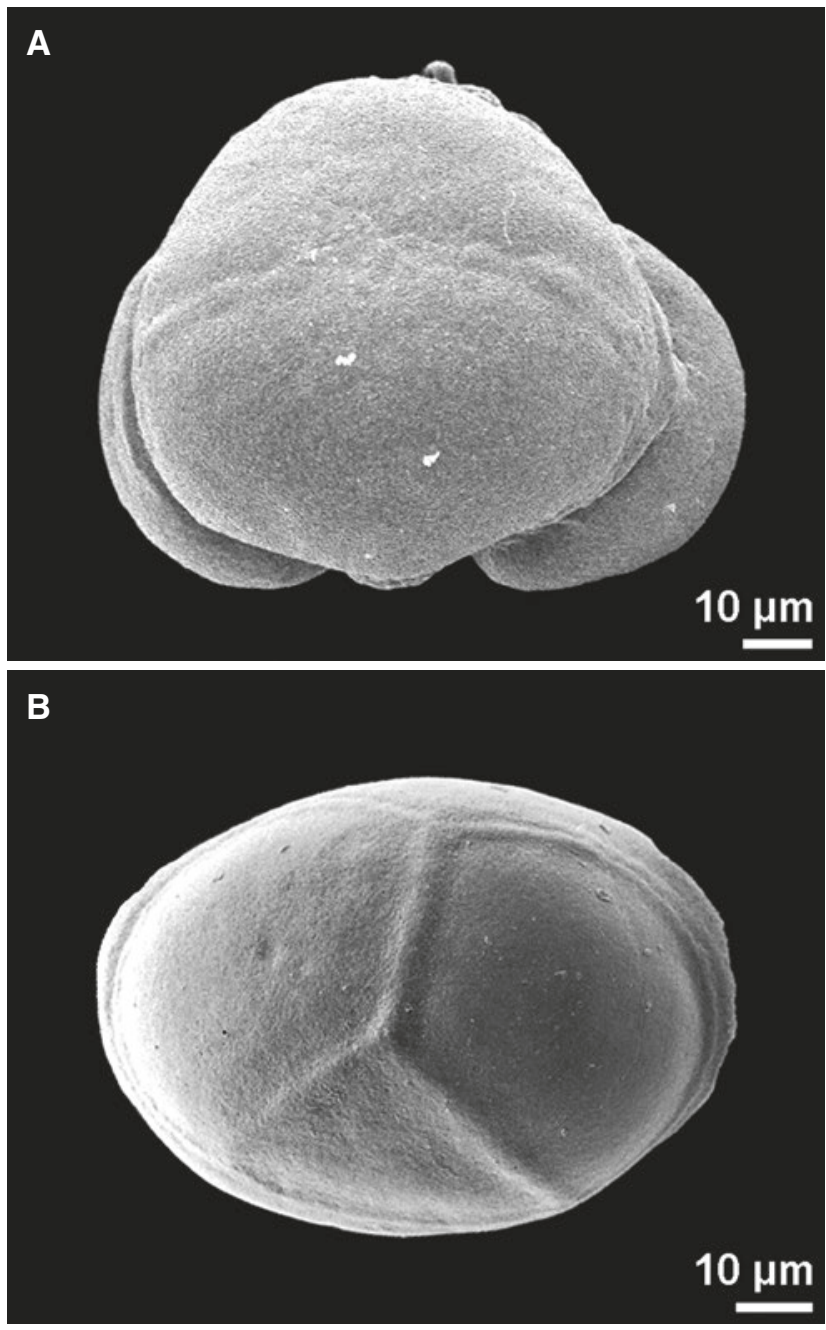

C

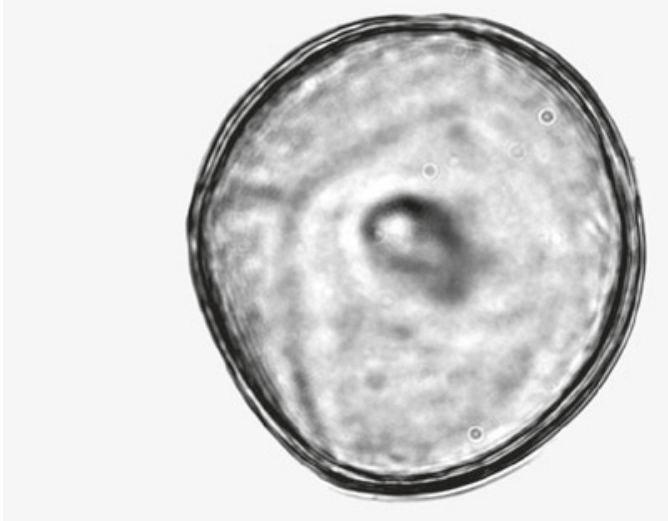

$10 \mu \mathrm{m}$

Fig. 1 Impression mark. A. Abies cephalonica, Pinaceae, proximal polar view, indistinct impression mark. B-C. Larix sp., Pinaceae, fossil, middle Miocene, Austria, proximal polar view, Y-shaped impression mark in SEM (B) and LM (C) 

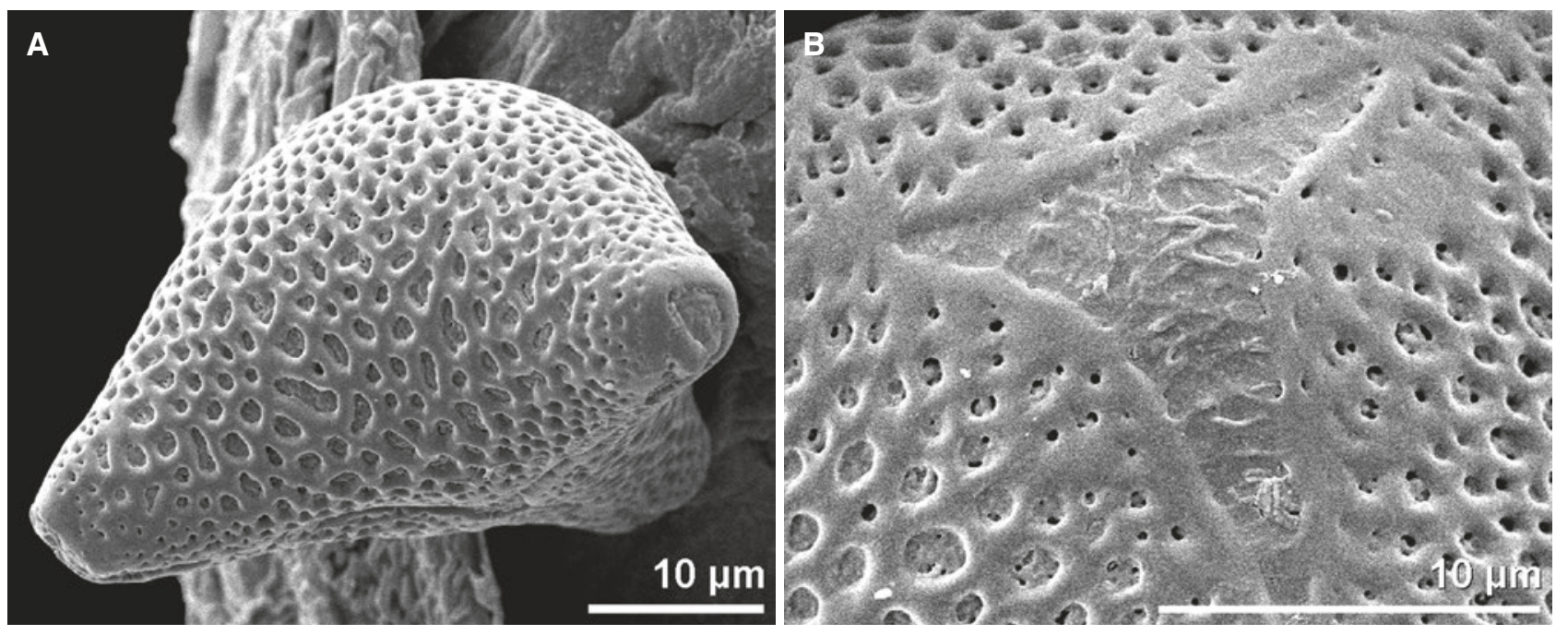

Fig. 2 Triangular tenuitas. A-B. Cardiospermum corindum, Sapindaceae, tricolporate, equatorial view (A), proximal pole with triangular thinning area (B)
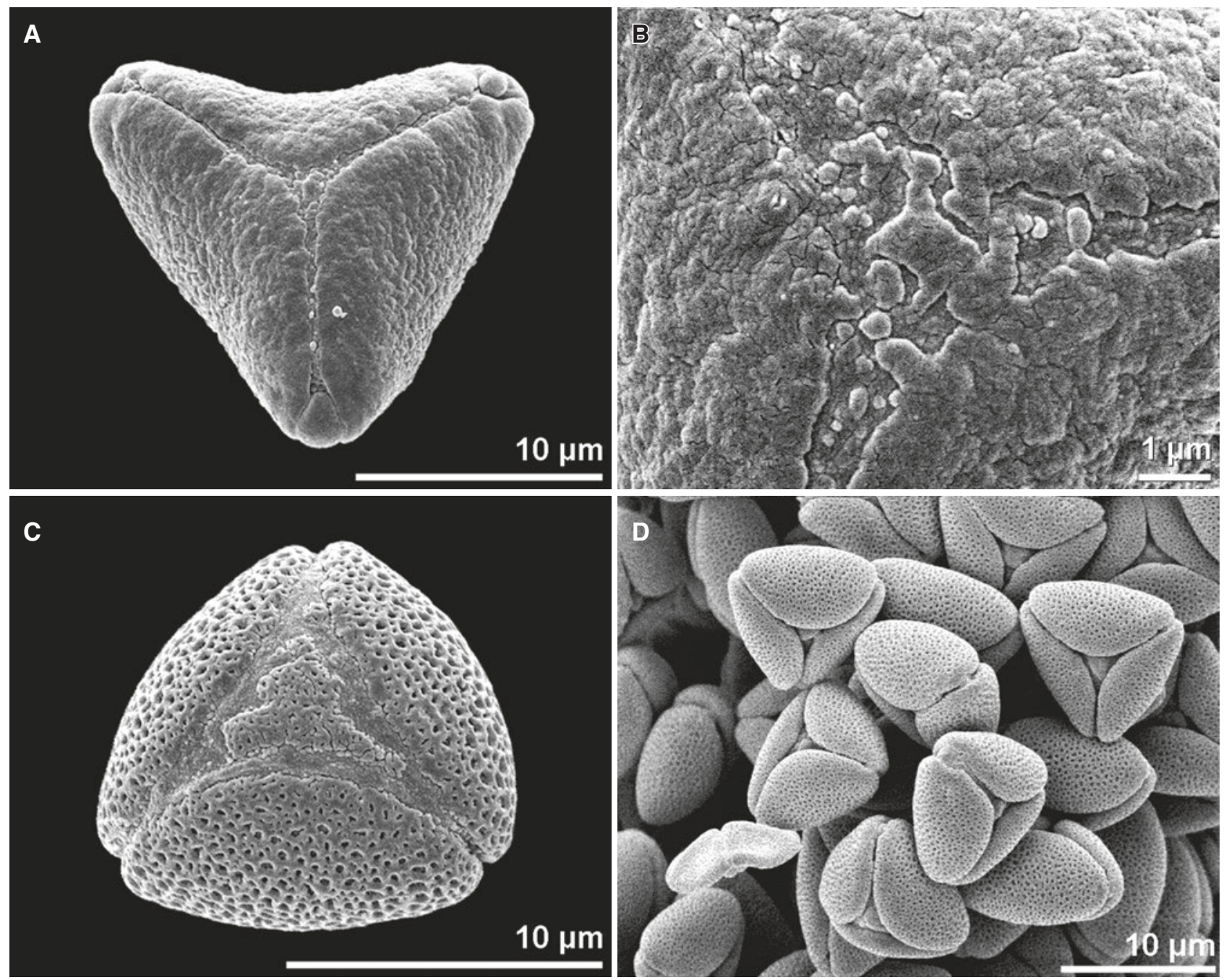

Fig. 3 Synaperturate pollen. A-B. Melaleuca armillaris, Myrthaceae, syncolporate, polar view (A), close-up of polar area (B). C. Primula denticulata, Primulaceae, syncolpate, polar view. D. Primula farinosa, Primulaceae, syncolpate, dry pollen 
three colpi, extending towards and merging at the poles. The pollen is therefore synaperturate (syncolpate, syncolporate). In for example, Primula the colpi dissect in the polar area, leaving a triangular field at both poles.

\section{Example 4: Tripartite Feature in Angiosperms - Trichotomosulcus}

A nother tripartite feature is the trichotomosulcus (Harley 2004), a three-armed sulcus occurring exclusively distally, as, e.g., in Dianella. Trichotomosulcate pollen has been discussed in relation to the evolution of the tricolpate dicot condition, but so far without success (Fig. 4).
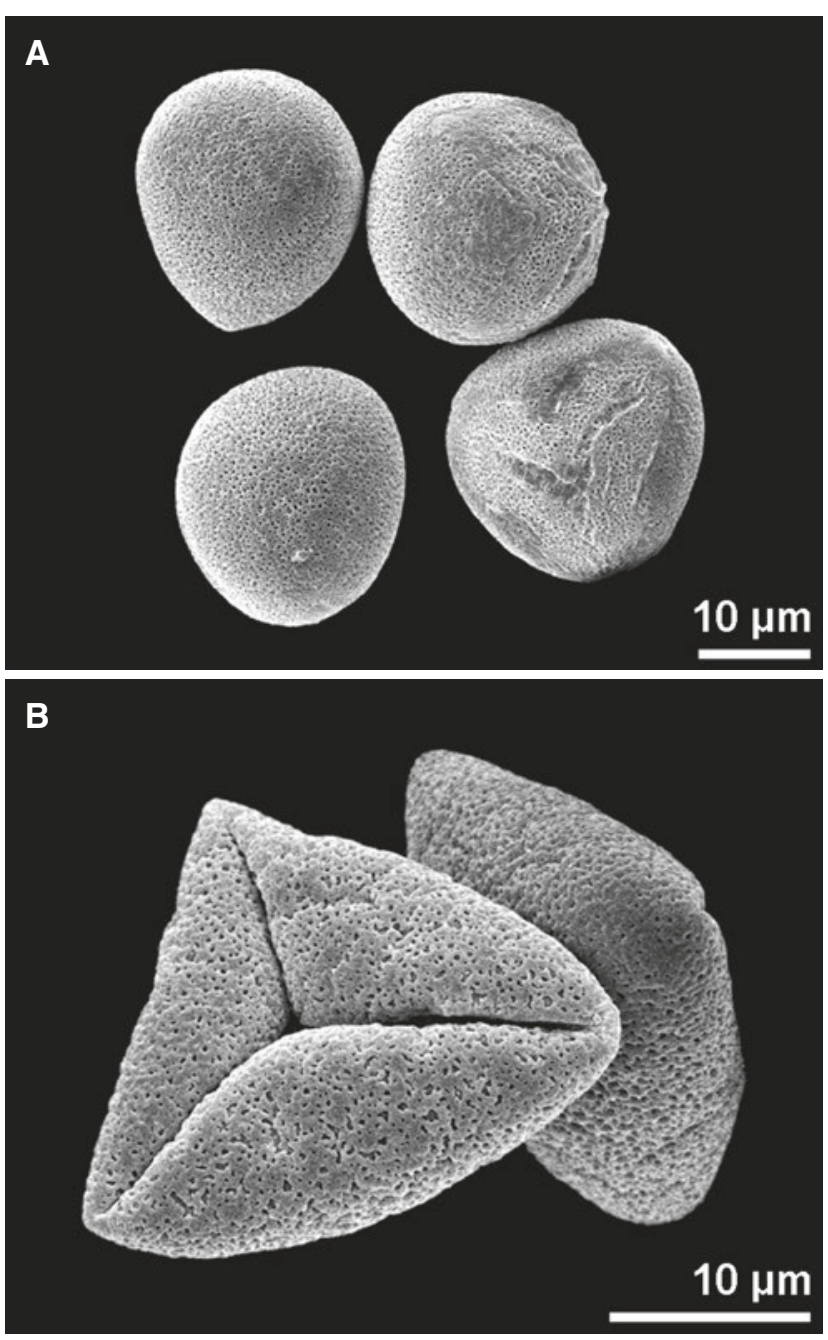

Fig. 4 Trichotomosulcus. A-B. Dianella tasmanica, Phormiaceae, trichotomosulcus (A), dry pollen, aperture infolded (B)

\section{Example 5: Tripartite Feature in Angiosperms - Sulci vs. Colpi vs. Tenuitas}

T he angiosperm-like pollen of the fossil genus Eucommiidites is "trisulcate": a broad distal sulcus and two narrower additional "sulci" (at angles of c. $120^{\circ}$ seen from the main sulcus; Fig. 5). This feature was erroneously interpreted as tricolpate pollen (with colpi equatorially situated).

A similar arrangement of a distal sulcus and two small additional sulci on the proximal face was described, for example, in some species of Tulipa (Liliaceae) and Tinantia (formerly Commelinantia, Commelinaceae), but these cases were never interpreted as equivalent to a tricolpate condition (Harley 2004) (Fig. 6). The two small additional sulci may also be interpreted as tenuitates. In some cases the three "sulci" are of similar size. The aperture condition is very similar to a tricolpate one.

\section{Example 6: Tripartite Feature in Angiosperms - Triradiate Aperture}

A nother three-armed feature is the triradiate aperture in Thesium alpinum (Santalaceae) pollen. The heteropolar pollen is 3-aperturate, with apertures placed in the three tapered edges of a tetrahedron (Fever 1977). Each aperture has a very inconspicuous triradiate outline, which is situated equatorially. Two of the arms point towards the neighboring tetrahedron edge and are rather short; the third, elongated arm is directed towards the rounded pole (Fig. 7).

\section{Example 7: Apertures in Angiosperms - Planaperturate}

ometimes apertures are inconspicuous and not discernible at first sight. In pollen of Pachira - aquatica (Malvaceae) three large, more-or-less hemispherical areas are seen equatorially, which may at first sight be interpreted as pores. However, a detailed observation reveals planaperturate pollen grains with three short colpi (Fig. 8). 
A

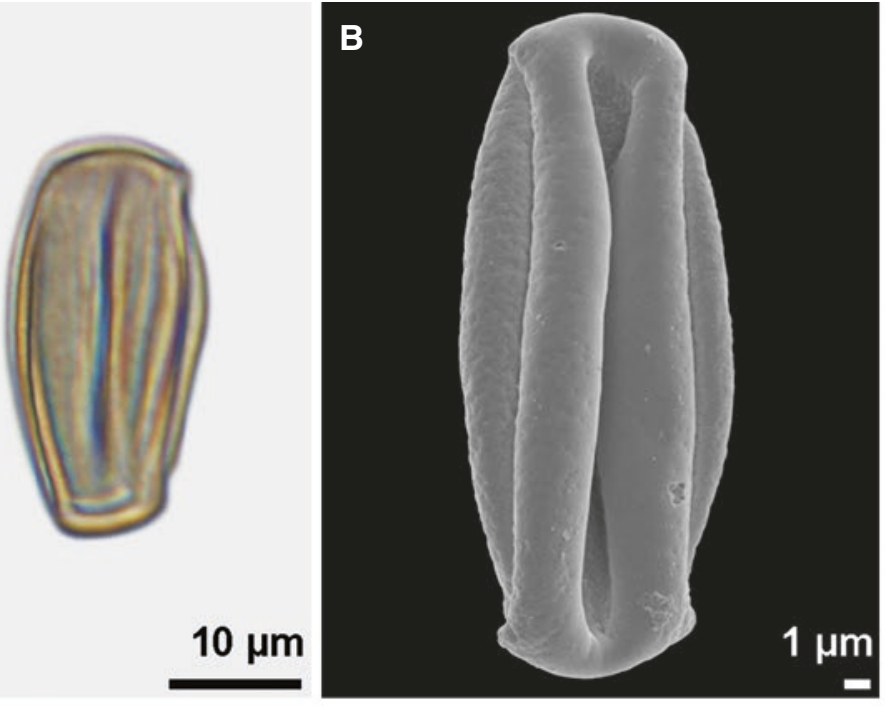

D

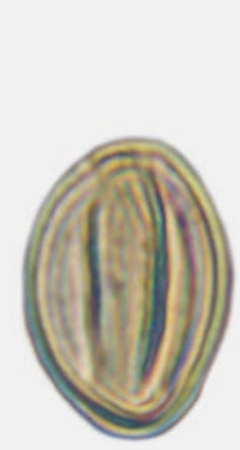

$10 \mu \mathrm{m}$
E

ש

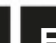

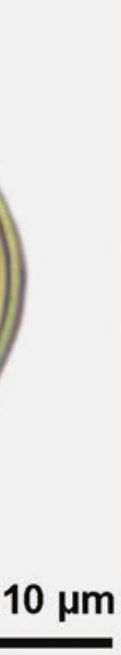

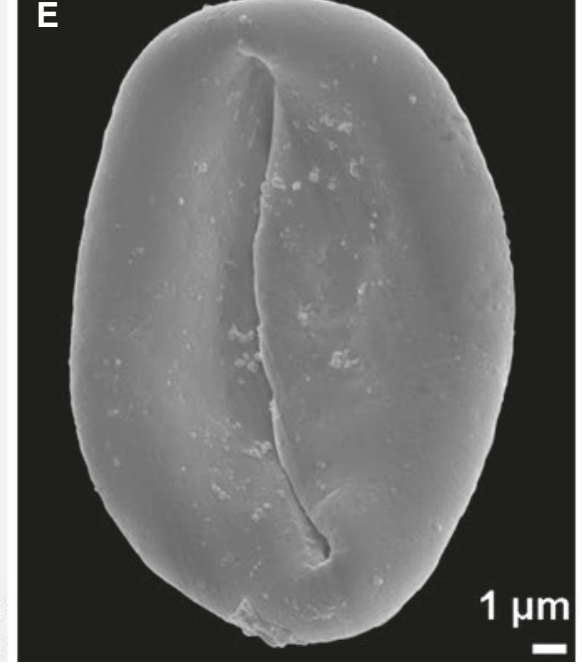

C

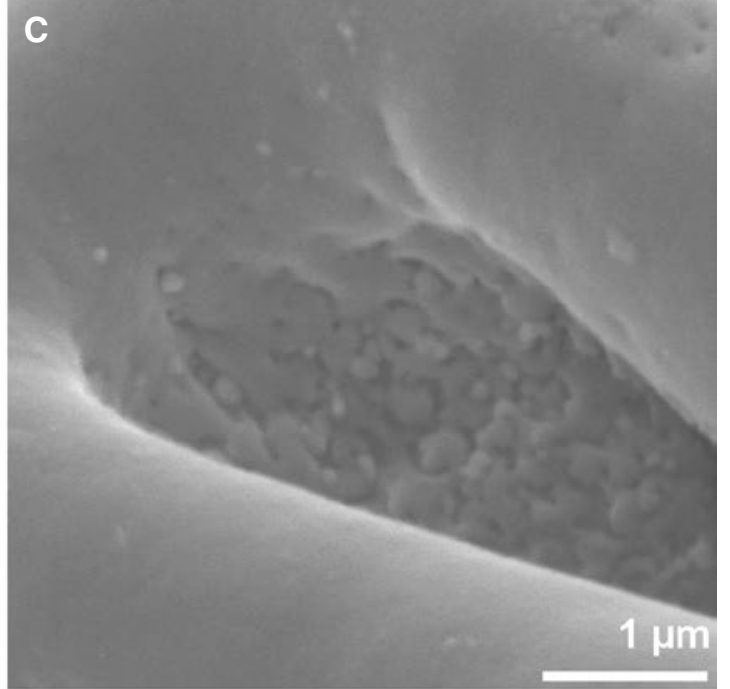

$\mathbf{F}$
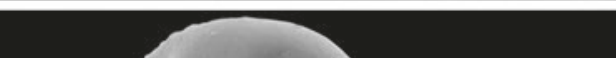

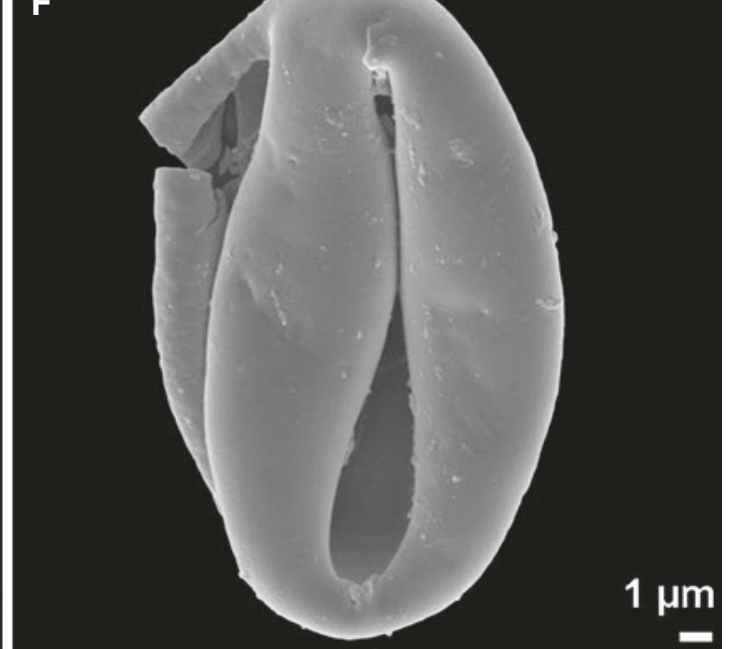

Fig. 5 Trisulcate pollen. A-C. Eucommiidites sp., fossil pollen, Lower Cretaceous of U.S.A., main sulcus with membrane seen in center of pollen grain, flanked by additional narrow sulci on each side (at angles of C. $120^{\circ}, \mathbf{A}-\mathbf{B}$ ), close-up showing sulcus membrane of main sulcus (C). D-F. Eucommiidites sp., fossil pollen, Lower Cretaceous of U.S.A., Narrow lateral sulcus (E), same grain turned showing the main broad sulcus and one narrow lateral sulcus (F)

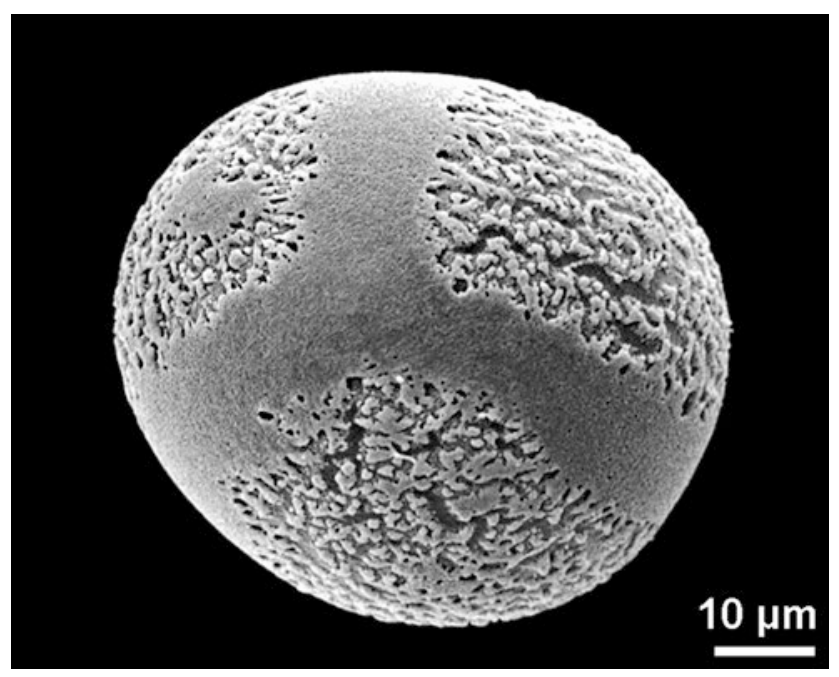

Fig. 6 Trisulcate pollen. Tulipa kaufmanniana, Liliaceae, trisulcate or sulcate with two tenuitates, equatorial view 

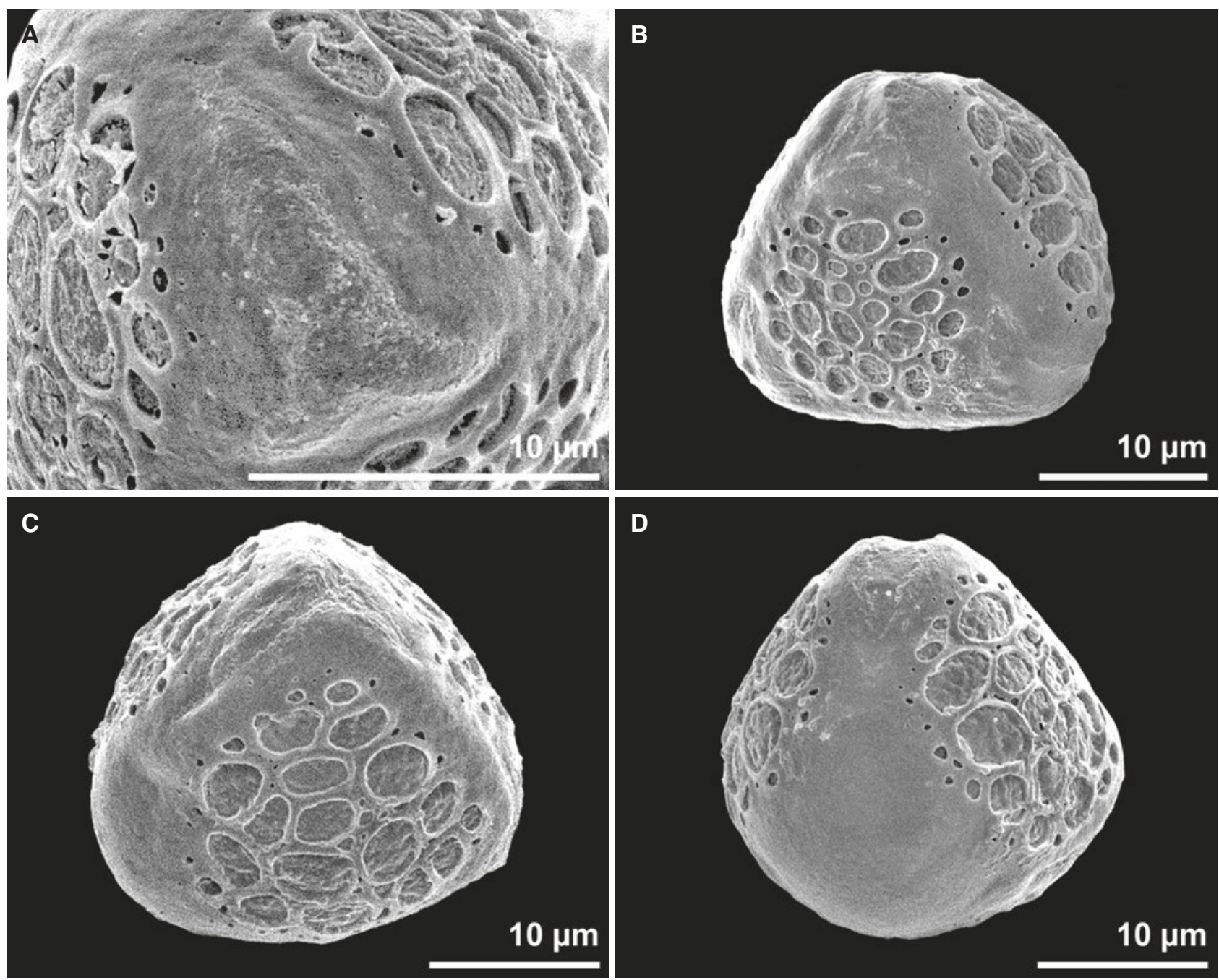

Fig. 7 Triradiate aperture. A-D. Thesium alpinum, Santalaceae. A. Tricolpate, heteropolar, triradiate colpus. B. Polar view (flattened pole). C. Equatorial view. D. Polar view (rounded pole)

\section{Example 8: Apertures in Angiosperms - Inconspicuous Pori}

1 $n$ Calliandra emarginata (Mimosaceae) the monads forming a polyad are separated by narrow groove-like depressions. At low magnification the presence and localization of the apertures remain indistinct; high SEM magnification reveals that the apertures are very inconspicuous pores, situated equatorially, usually at the conjunction of three or four monads (Fig. 9 A, B).

Also, the aperture condition may be overlooked due to other eye-catching features. The clypeate pollen of Phyllanthus $x$ elongatus (Euphorbiaceae) seems to be inaperturate. Only close-ups reveal the inconspicuous few pores between the exine shields (Fig. 9 C, D).

\section{Example 9: Apertures in Angiosperms - Inconspicuous Colpi}

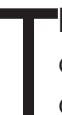
he disc-like pollen of Oryctanthus sp. (Loranthaceae) shows at both poles conspicuous circular depressions that are not apertures (Fever and Kuijt 1985; Grímsson et al. 2018). The pollen is according to Grímsson et al. (2018) demi(3)colpate, with 
A

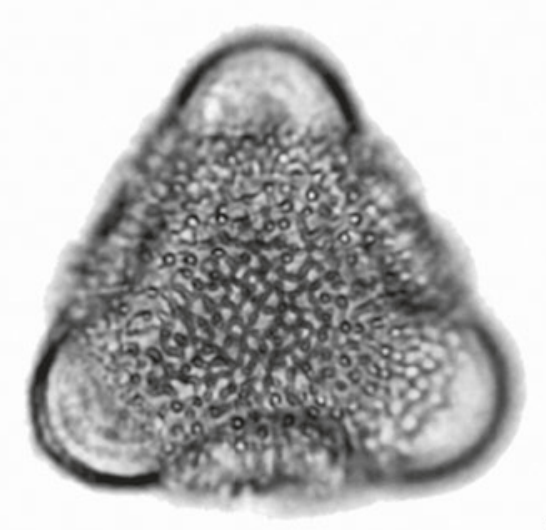

$10 \mu \mathrm{m}$

B
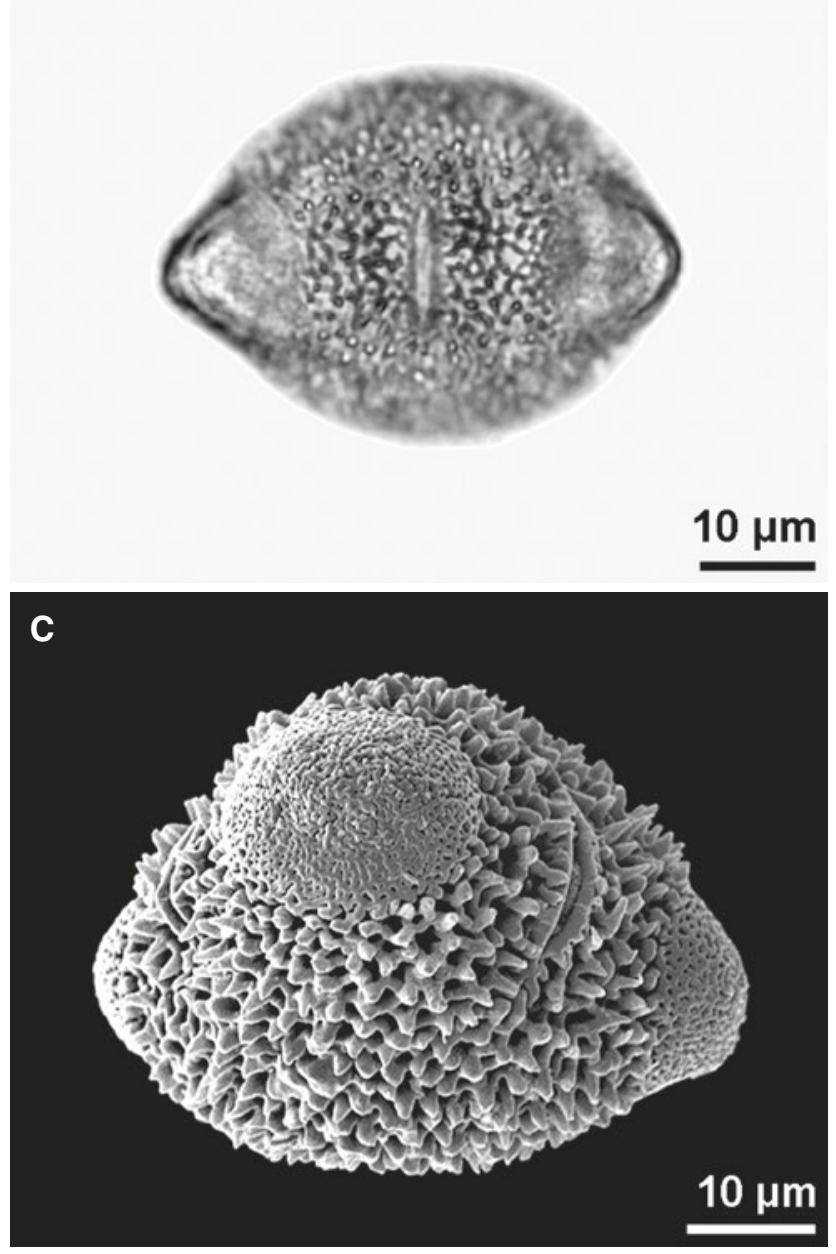

Fig. 8 Planaperturate pollen. A-C. Pachira aquatica, Malvaceae, polar view (A), equatorial view (B), oblique equatorial view (C) inconspicuous slit-like colpi positioned between the polar depressions (Fig. 10). Another example are some Asteraceae pollen, where the colpi are often inconspicuous or not visible in SEM, but obvious in LM.

\section{Example 10: Apertures in Angiosperms - Hidden Apertures}

R ecent and fossil triaperturate (colpate or porate) pollen of Trapa (Trapaceae) is distinguished by unique meridional exine ridges (crests) covering the apertures (Zetter and Ferguson 2001) (Fig. 11).

\section{Example 11: Apertures \\ in Angiosperms - Ring-like Apertures vs. Colpate-Operculate}

$\mathrm{T}$ he apertures in Passiflora cf. incarnata may be interpreted as three ring-like apertures or may be interpreted as pori (or colpi) each with an operculum. In other species of Passiflora e.g., P. citrina and $P$. suberosa, the apertures are both narrower and stephanocolpate (Fig. 12).

\section{Example 12: Apertures in Angiosperms - Tenuitas vs. Poroid}

Tenuitas is a general term for a pollen wall thinning (Kremp 1968; Harley 2004; Punt et al. 2007). It is normally found additional to apertures, e.g., in Myosotis (Fig. 13). A circular tenuitas can be mistaken for a poroid, which is a circular or elliptic aperture with an indistinct margin (see also "lllustrated Pollen Terms").

\section{Example 13: Apertures}

in Angiosperms - Infoldings vs. Apertures

W hen pollen is infolded it can be hard to distinguish the apertures. Pollen of Sparganium erectum (Sparganiaceae) is in dry stage infolded, boat-shaped, and would be considered as sulcate. In fact, Sparganium pollen is ulcerate, the ulcus is seen clearly in the hydrated, spherical pollen stage (Fig. 14). 

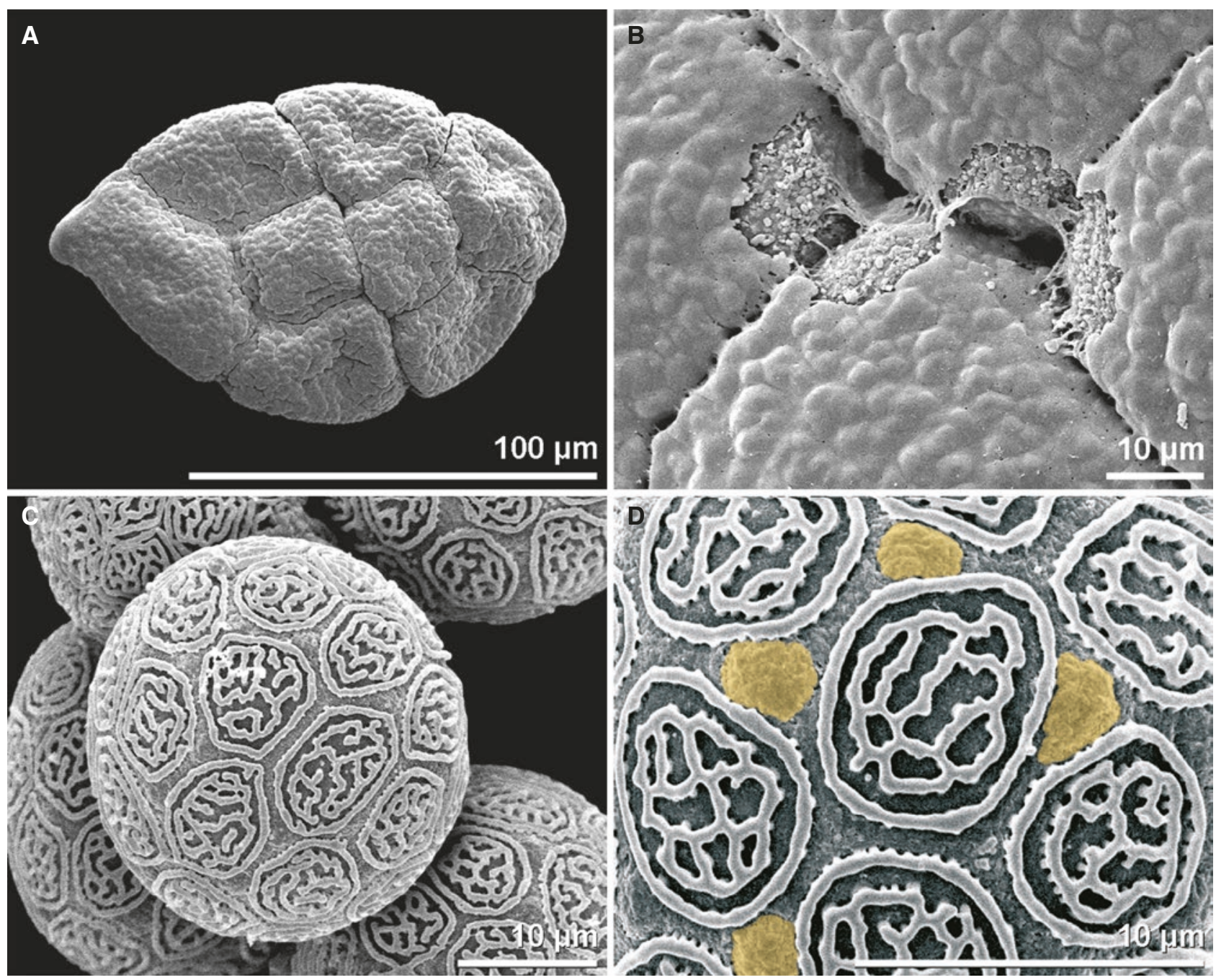

Fig. 9 Apertures in Calliandra and Phyllanthus. A-B. Calliandra tergemina, Fabaceae, polyad, dry state (A). Apertures (pori) at the junction of four monads (B). C-D. Phyllanthus x elongatus, Euphorbiaceae, clypeate, seemingly inaperturate (C), Inconspicuous pores (colored) between the exine shields (D)

\section{Example 14: Apertures}

in Angiosperms - Ulcerate-Operculate vs. Ring-like Aperture

$\mathrm{N}$ ymphaea alba (Nymphaeaceae) pollen has asymmetrical halves divided by a ring-like aperture (Fig. 15). The features of the smaller distal half may be misinterpreted as a large ulcus with a conspicuous operculum. Ultrastructural studies and germination experiments support the interpretation of a ring-like aperture (Gabarayeva and Rowley 1994; Hesse and Zetter 2005).
Example 15: Apertures in Angiosperms Disulcate vs. Dicolpate

7 he term disulcate defines two elongated apertures situated usually distally (but not directly at the distal pole), running parallel to or even in the equator (Fig. 16). If the apertures are running meridionally, pollen would be dicolpate (Halbritter and Hesse 1993). To distinguish if the pollen is disulcate or dicolpate it is important to study the pollen in tetrad arrangement to clarify the polarity and position of apertures (see Fig. 3 in "Methods in Palynology"). 


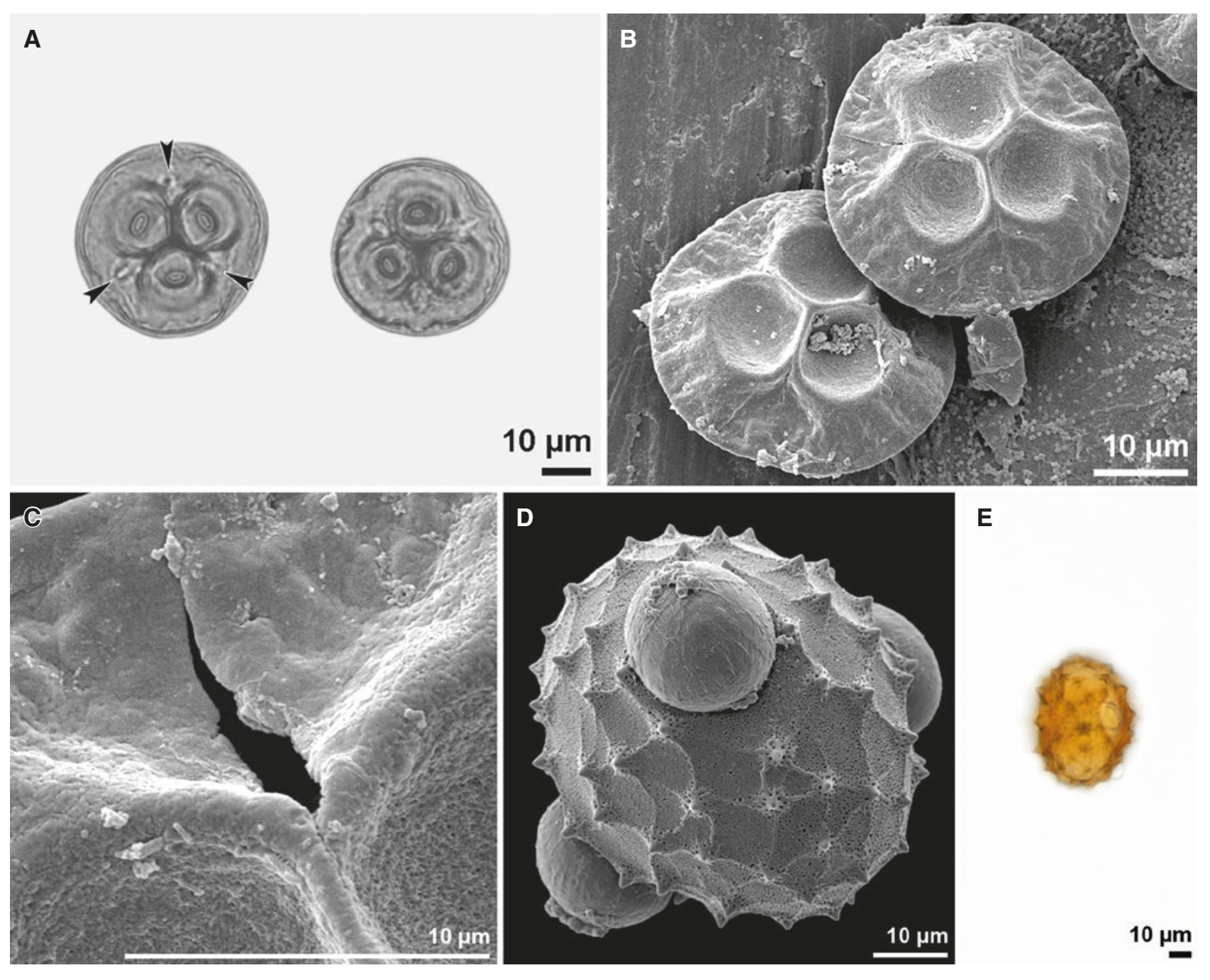

Fig. 10 Apertures in Oryctanthus. A-C. Oryctanthus alveolatus, Loranthaceae, acetolyzed pollen, arrowheads point to colpi, LM (A). two grains in polar view, SEM (B). close-up showing colpus (C). D-E. Carthamus lanatus, Asteraceae, hydrated pollen, pollen in SEM seem porate (D). Acetolyzed pollen, colporus (highlighted) only visible in LM (E)

Examples for taxa with disulcate pollen are the monocots Tofieldia calyculata with one sulcus distally, the other proximally, Uvularia grandiflora, Eichhornia crassipes (Hesse et al. 2009), some Dioscorea species (Schols et al. 2005), Pontederia cordata (Halbritter 2016), Calla palustris (Ulrich et al. 2013), and the magnoliid Calycanthus floridus (Huynh 1976).

\section{Example 16: Apertures}

in Angiosperms - Zon-, Zono-, Zoni-, Zona- vs. Ring-like Aperture and Stephanoaperturate Pollen

T erms combining the basic prefix zon- together with its linguistic derivatives are a source of endless confusion, misunderstanding and superflu- ous inflation of terms. The prefix include zon- (in zonorate, for a ring-like endoaperture, the os, at the equator), the outdated, rarely used zoni- (however, with two quite different terminological applications), but especially zona- (indicating exclusively a ring-like feature situated anywhere) and zono(indicating any feature located strictly equatorially).

Terms for ring-like (aperture) features include zona-aperturate, zona-sulculus (addressing the polarity by anazona-sulculus and catazonasulculus), zona-sulcus, zonate, zono-aperturate, and also related names (e.g., "fully zonate condition" sensu Grayum 1992). Even the misleading and contradictory zono-sulcus (a sulcus cannot be situated equatorially) is used instead of the correct, but phonetically confusable, zona-sulcus. Even the 
A

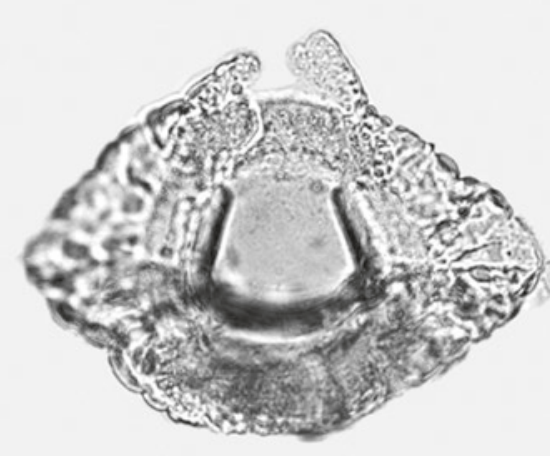

$10 \mu \mathrm{m}$
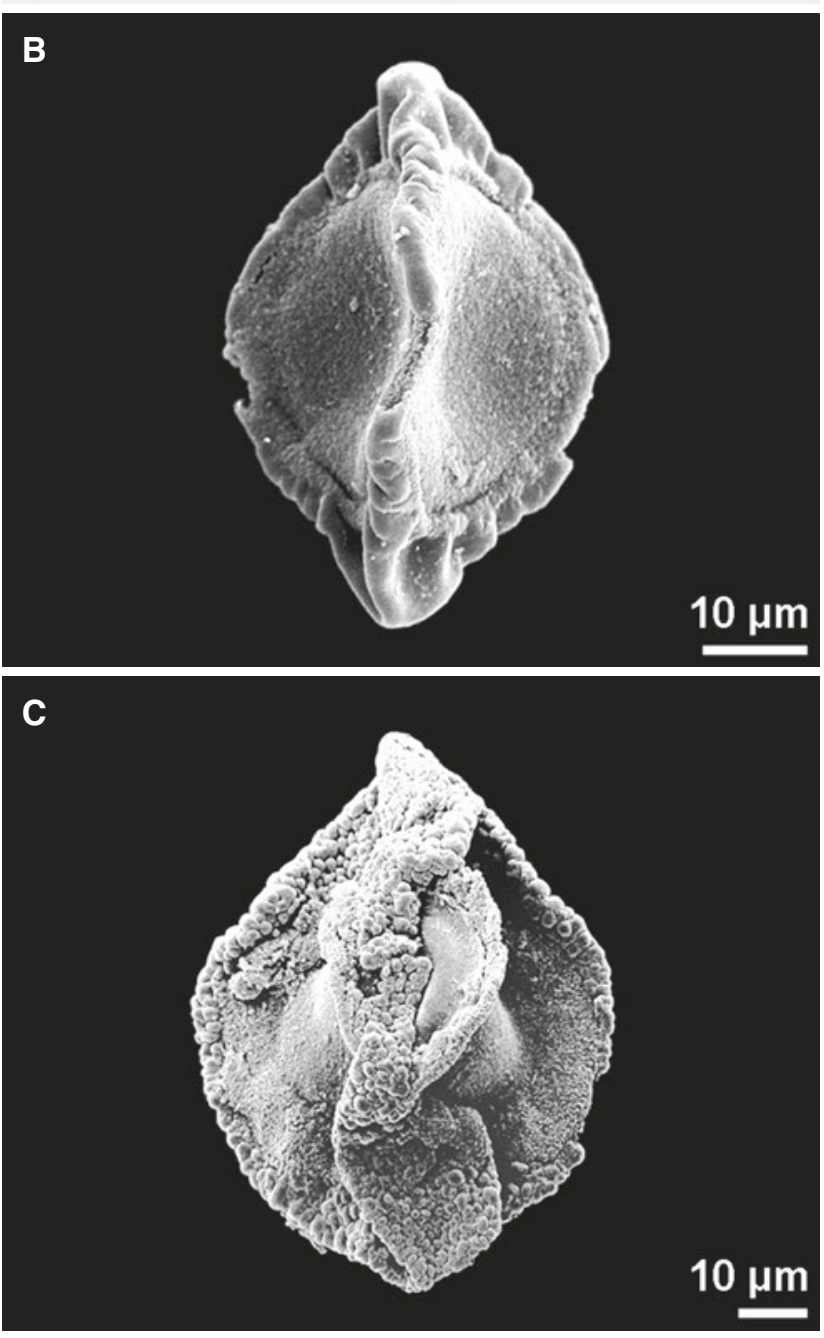

Fig. 11 Apertures in Trapa. A-C. Trapa sp., Trapaceae, fossil, late Miocene, Austria, equatorial view, crest broken, LM (A). Equatorial view, crest partly broken, colpus visible in SEM (B). Equatorial view, SEM (C) trained palynologist may become confused. Therefore, all these terms should be avoided and we recommend the following two terms: ring-like aperture and stephanoaperturate (see "Illustrated Pollen Terms"). Any encircling aperture ("zonaaperturate"), irrespective of meridional or equatorial location, is simply called a ring-like aperture. Any case with more than three apertures at the equator ("zono-aperturate") is called stephanoaperturate.

\section{Example 17: Magnification Effect- Retipilate vs. Reticulum Cristatum}

$T$ he term retipilate (reticuloid) describes a reticulum formed by pila instead of muri (Erdtman 1952). Combined investigations based on LM and SEM have revealed that the given examples Callitriche (Punt et al. 2007) and Cuscuta lupuliformis (Erdtman 1952) do not fit the definition of retipilate. In fact, the reticulum consists of muri with prominent suprasculpture elements and are without isolated pilae. Such ornamentation is termed reticulum cristatum (a special type of reticulum; muri with prominent suprasculpture elements; Fig. 17, see also "Illustrated Pollen Terms"). So far no example for retipilate sensu Erdtman (1952) is currently known.

\section{Example 18: Dispersal Units - Massula vs. Polyad}

tor or a pollen dispersal unit of more than four pollen grains two terms are in use, massula and polyad (Fig. 18). The application of both terms is confusing and inconsistent in the literature. Often, the various authors employ the terms more or less interchangeably and do not provide a sharp delimitation (Walker 1971; Wagenitz 2003; Punt et al. 2007; Traverse 2007). These terms, however, are not exchangeable for historical and practical reasons (see extensive review by Teppner 2007).

The term massula was coined by Richard (1817) for parts of a pollinium in some Orchidaceae and should be used for the subunits of orchid sectile pollinia/pollinaria. Massulae within one and the same pollinium are variable and different in shape, size, and numbers of pollen grains. Unfortunately, the term massula has also been used to designate compound pollen in various other families, e.g. 

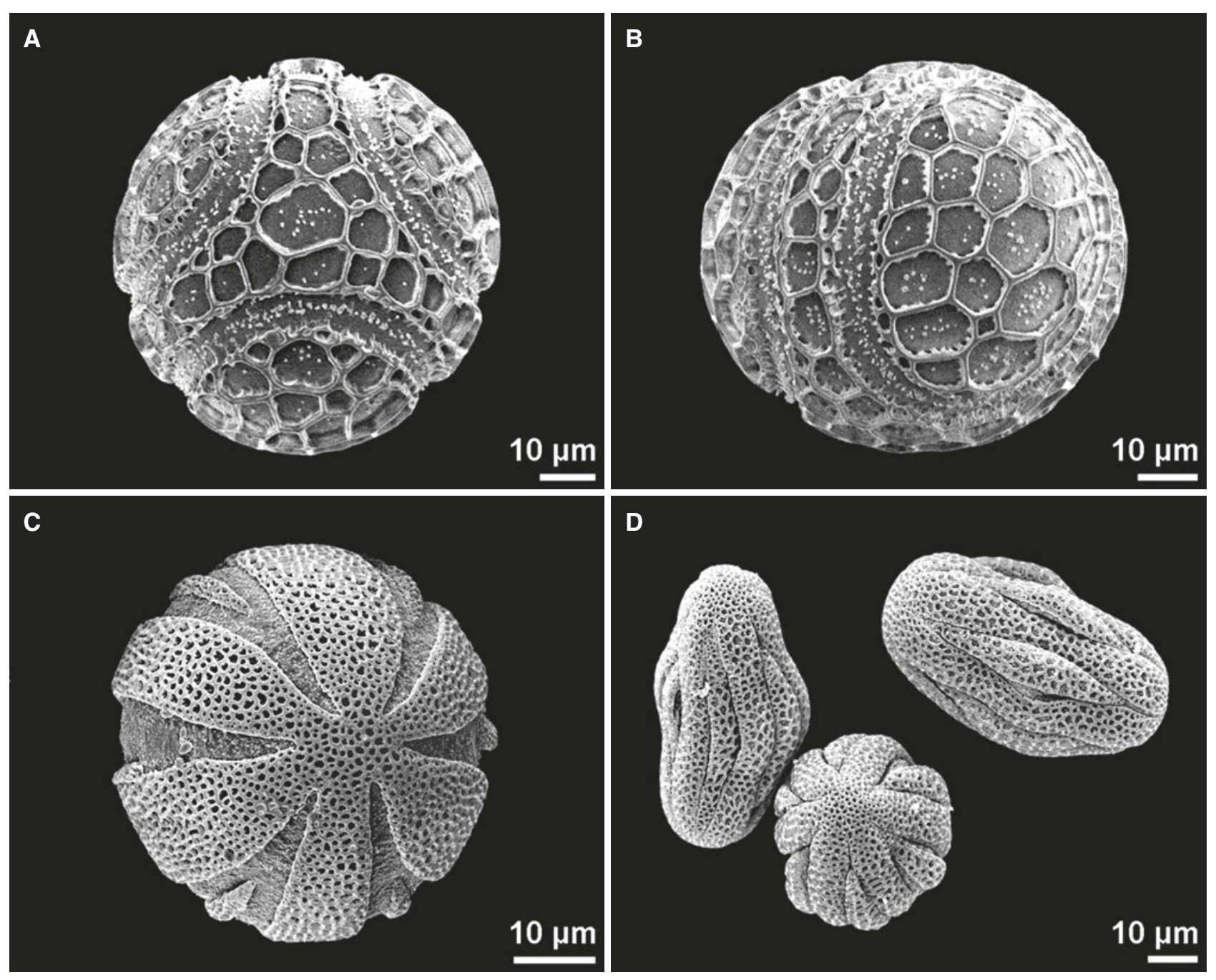

Fig. 12 Apertures in Passiflora. A-B. Passiflora cf. incarnata, Passifloraceae; colpate, operculate aperture, polar view (A), equatorial view (B). C. Passiflora citrina, Passifloraceae, stephanocolpate, operculate, polar view. D. Passiflora suberosa, Passifloraceae, stephanocolpate, operculate, dry pollen

Fabaceae-Mimosoideae, producing dispersal units of more than four pollen grains (e.g., Wettstein 1907; Wagenitz 2003; Punt et al. 2007). For these the term polyad - coined by Iversen and Troels-Smith (1950) - should be used, denoting a symmetric dispersal unit of more than four regularly arranged and permanently united pollen grains. Polyads, currently known to occur in Fabaceae (Mimosoideae), Gentianaceae, Hippocrateaceae, Celastraceae and Annonaceae, contain a specific number of pollen grains (a multiple of four: 8 , $12,16,24,32,48,64)$ and show a species-specific shape.
Example 19: Preparation Effect — Psilate vs. Ornamented

O rnamentation sometimes depends on the preparation method. A striking example is pollen of many Aroideae (Araceae), that are ornamented (e.g., echinate, striate, verrucate) in fresh or dry condition, but become psilate following acetolysis (Fig. 19). The outer pollen wall layer and ornamentation elements are composed of polysaccharide (lack sporopollenin) and are therefore destroyed during acetolysis (Weber et al. 1999; Ulrich et al. 2017). 

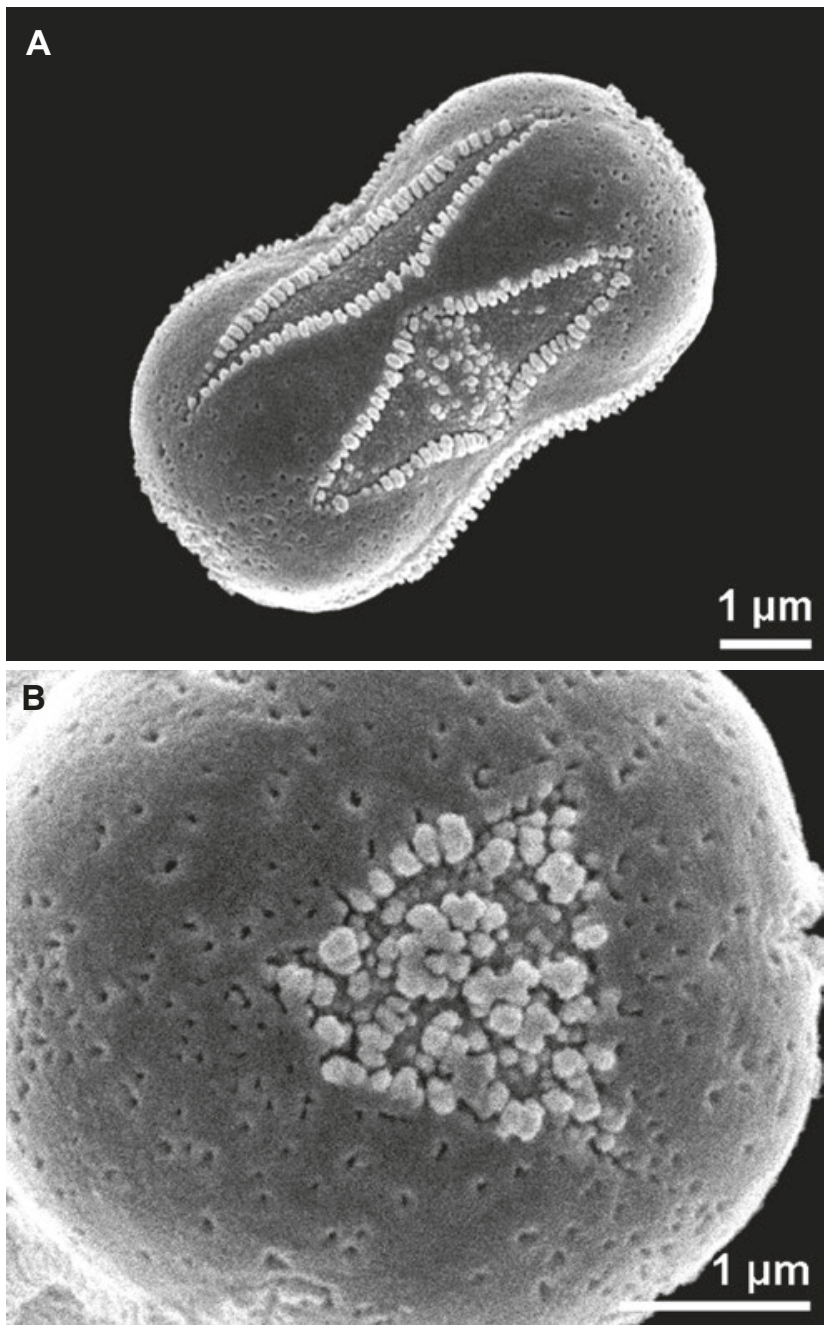

Fig. 13 Tenuitas vs. poroid. A-B. Myosotis palustris, Boraginaceae, equatorial view, heteroaperturate, alternating colpori and pseudocolpi (A), polar view, polar area with triangular tenuitas (B)

\section{Example 20: Preparation Effect - Areolate-Fossulate vs. Verrucate}

$\mathrm{T}$ he dehydration process with 2,2-dimethoxypropane (DMP) and critical point drying (CPD) for SEM investigations can affect the ornamentation. An example for different interpretations in relation to a varying degree of hydration is Trichosanthes anguina (Cucurbitaceae), where the ornamentation can reflect different degrees of hydration. The ornamentation can be described as areolate and fossulate in partially hydrated condition or verrucate and perforate in fully hydrated condition (Fig. 20).
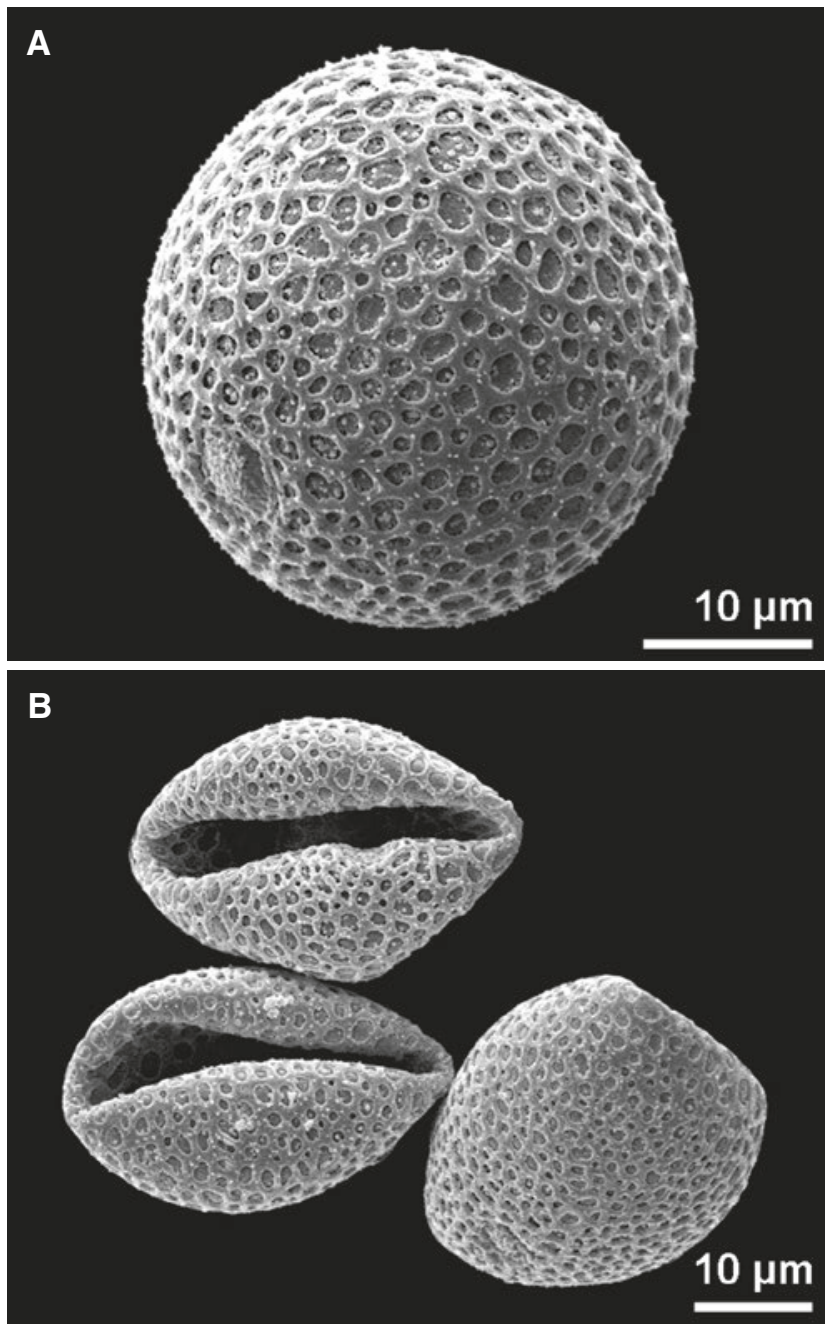

Fig. 14 Apertures in Sparganium. A-B. Sparganium erectum, Sparganiaceae, ulcerate, equatorial view hydrated pollen (A), boat-shaped, dry pollen (B)

\section{Example 21: Preparation Effect — Striate vs. Striato-reticulate}

T he ornamentation of Amorphophallus longituberosus pollen in dry condition or hydrated in water is striate, but after critical point drying it becomes striate to reticulate. The striate to reticulate ornamentation of Amorphophallus longituberosus is a result of an expanding thin surface layer (Fig. 21 D). During rehydration, the expansion of the thin layer itself forms a reticulum (Fig. 21 C), which finally ruptures partly or completely (Ulrich et al. 2017). 


\section{A}
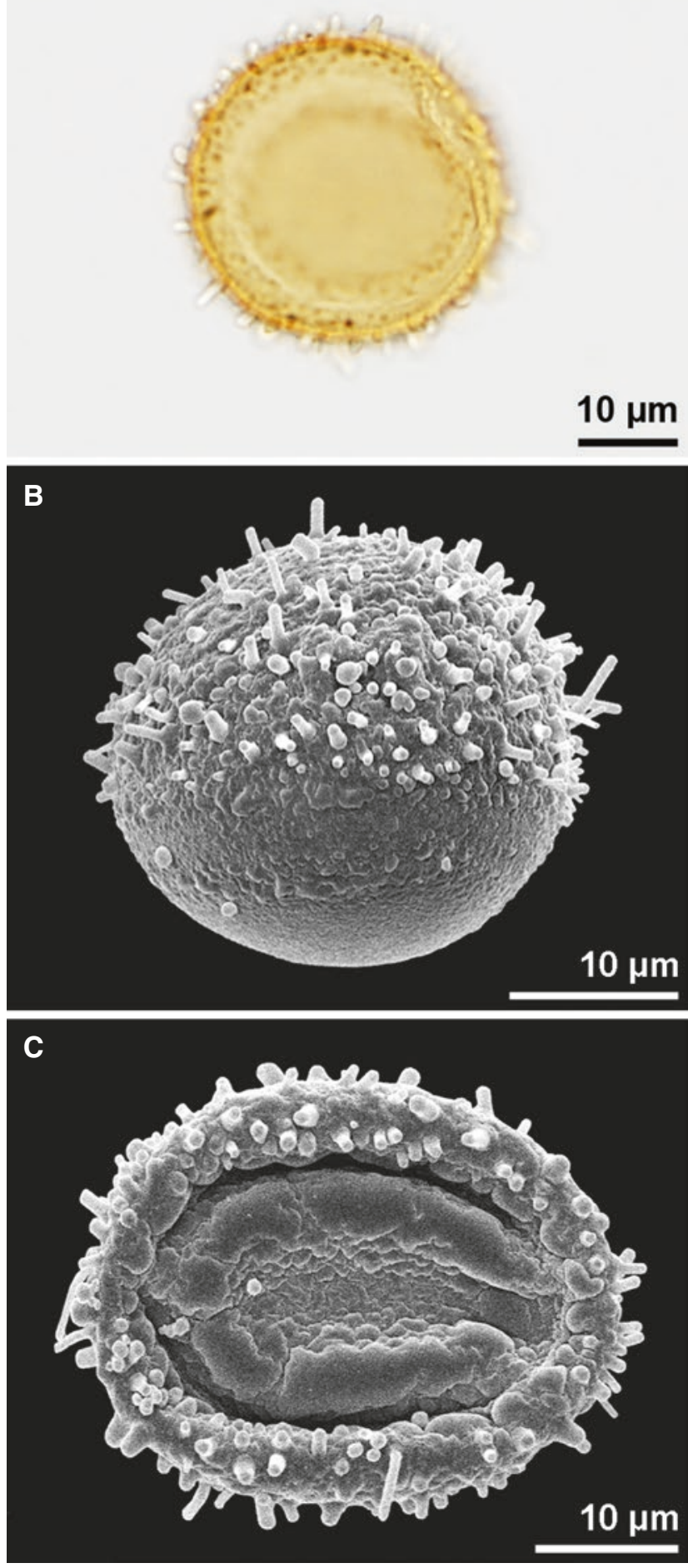

Fig. 15 Apertures in Nymphaea. A-C. Nymphaea sp., Nymphaeaceae; ring-like aperture, polar view (A), Ringlike aperture, equatorial view (B), dry pollen, cup-shaped (C)
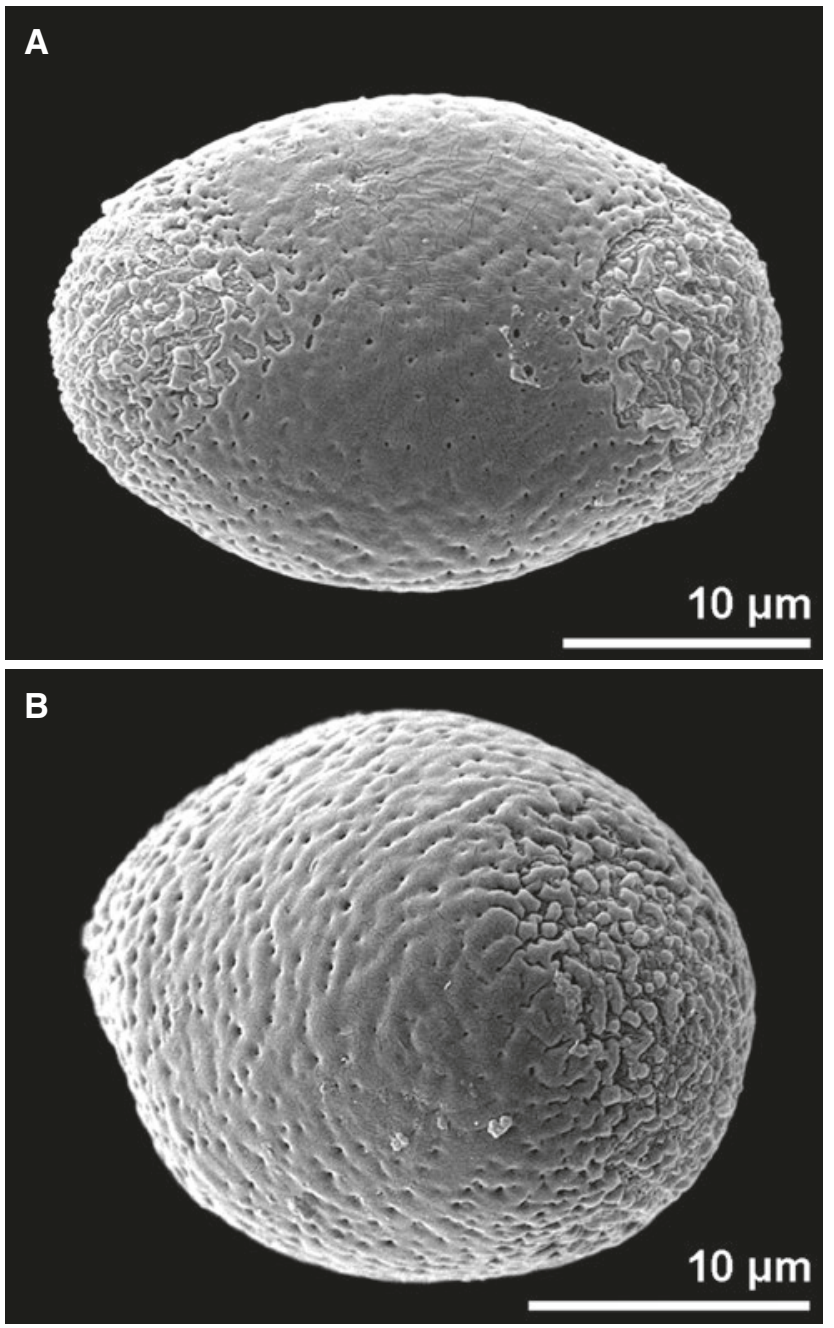

Fig. 16 Disulcate. A-B. Calla palustris, Araceae, polar and equatorial view 


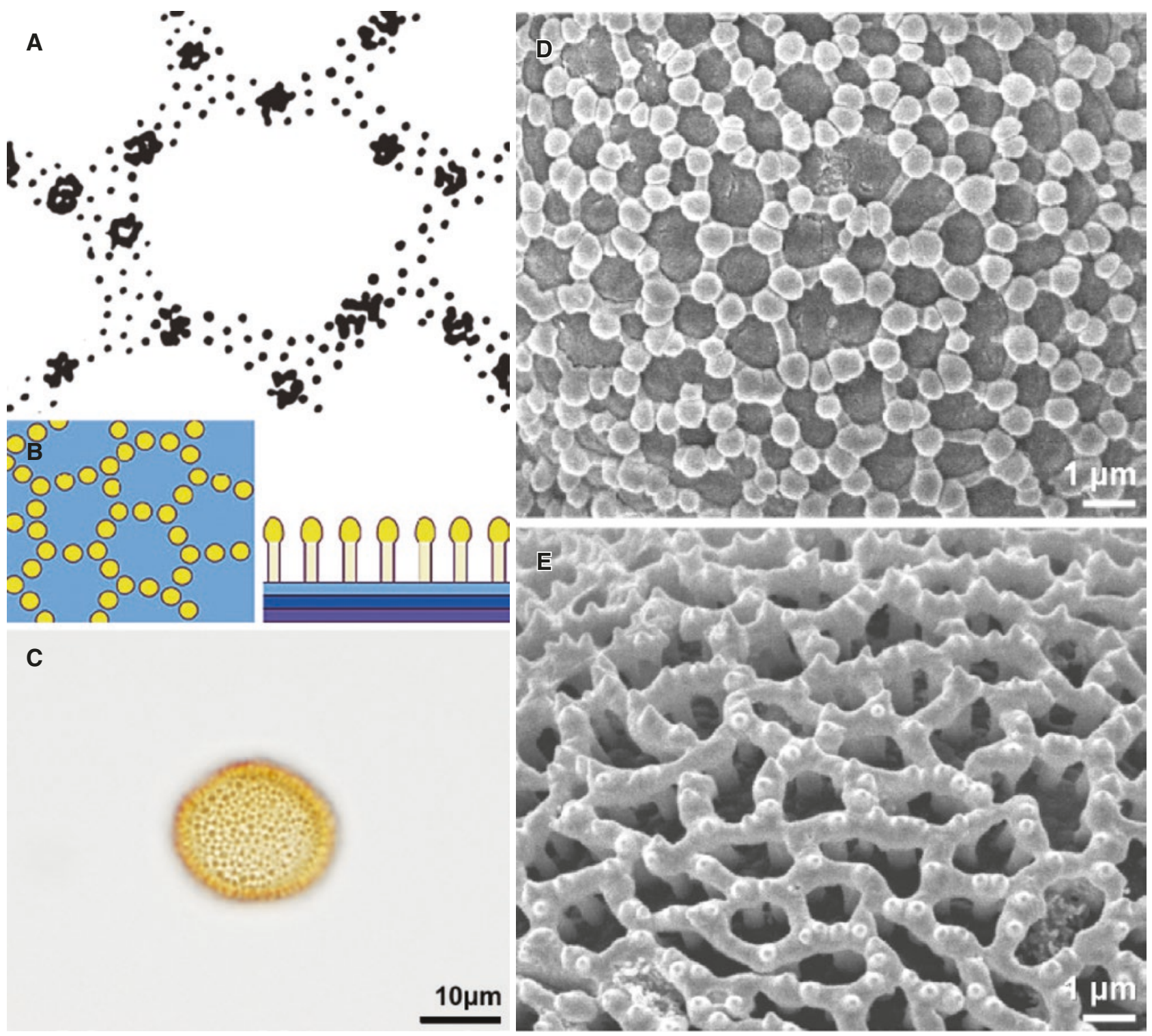

Fig. 17 Retipilate vs. reticulum cristatum. A. Drawing from Erdtman (1952). B. Drawings from Punt et al. (2007). C. Callitriche palustris, Plantaginaceae, acetolyzed pollen in LM. D. Callitriche polymorpha, Plantaginaceae, reticulum cristatum with small gemmae (suprasculpture) on thin muri. E. Cuscuta lupuliformis, Convolvulaceae, reticulum cristatum with nanoechini (suprasculpture)

Example 22: Staining Methods Absence or Presence of Endexine

7 he staining behavior of the endexine is very heterogeneous, even within the same plant family or the same genus (Weber and Ulrich 2010). There- fore, the endexine is often reported as absent even though the layer is actually present. In most studies on pollen ultrastructure, sections are stained with uranyl acetate and lead citrate only. To truly distinguish the presence of endexine one should/must apply potassium permanganate which stains the endexine electron dense (Fig. 22, see also "Methods in Palynology"). 

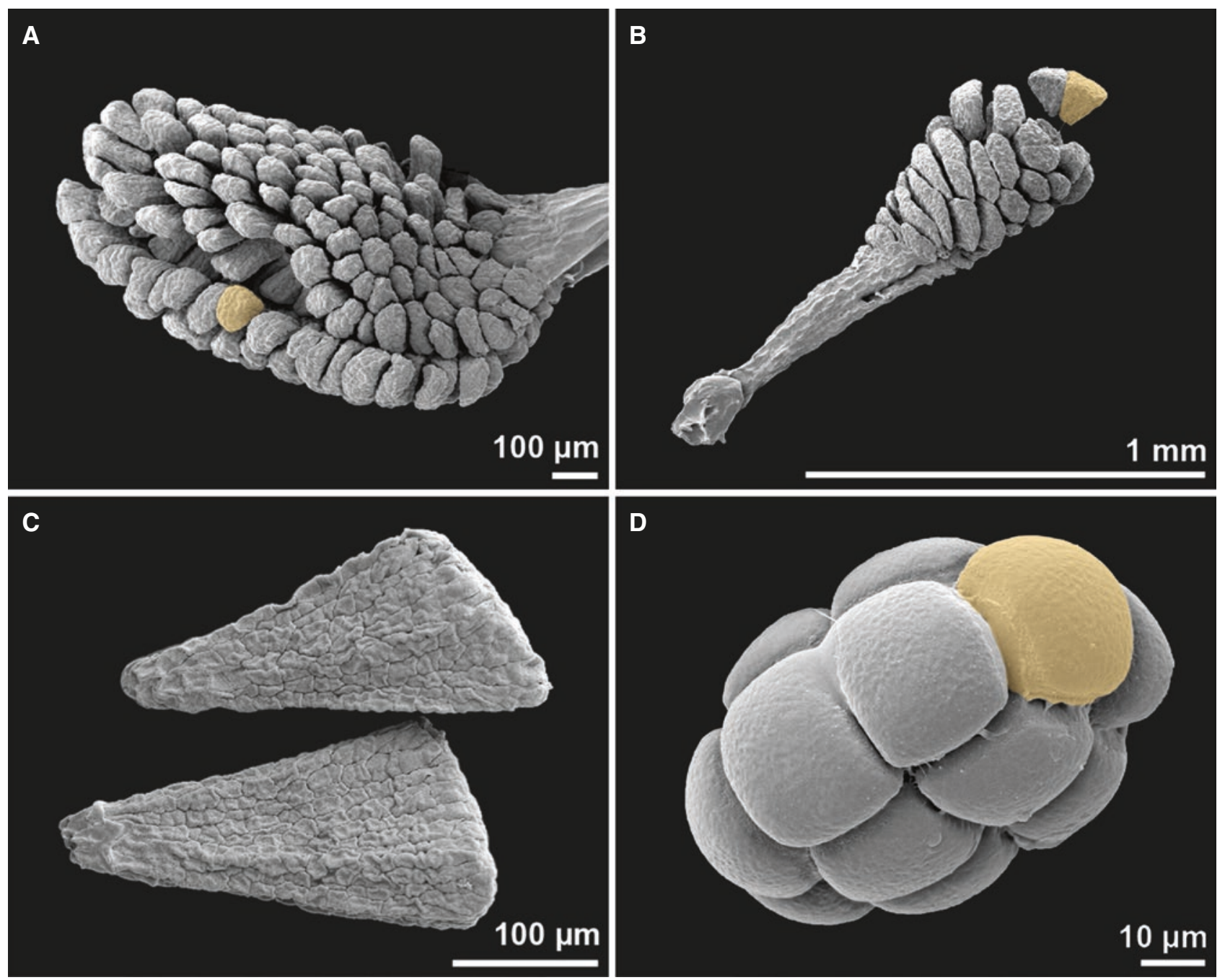

Fig. 18 Massula vs. polyad. A. Habenaria sp., Orchidaceae, pollinium composed of numerous massulae (massula highlighted). B. Orchis ustulata, Orchidaceae, pollinium composed of numerous massulae, two massulae partly segregated (massula highlighted). C. Ludisia discolor, Orchidaceae, 2 segregated massulae. D. Albizia julibrissin, Fabaceae, polyad (monad highlighted) 


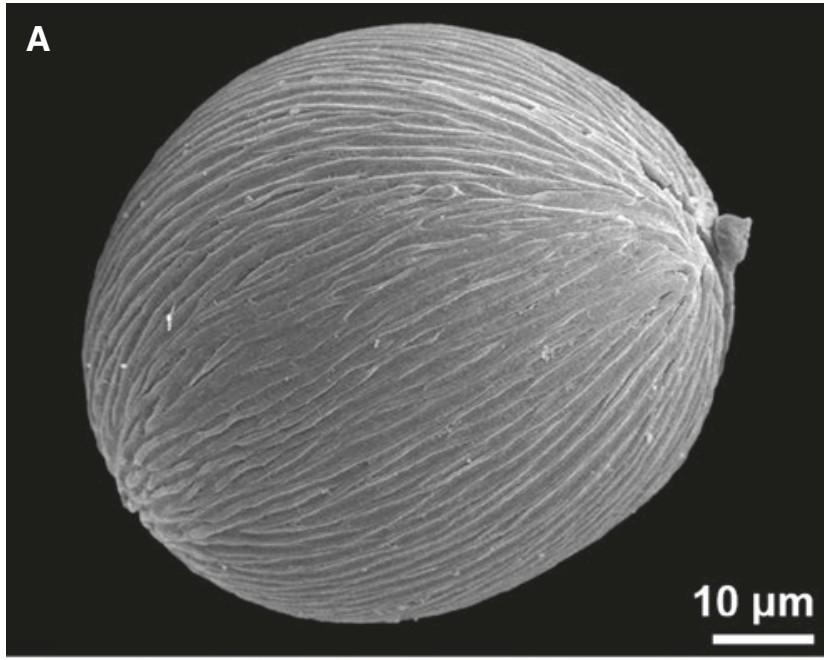

B

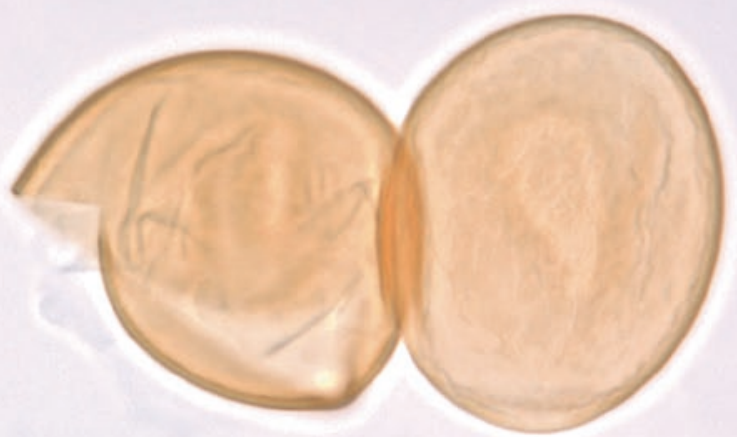

$10 \mu \mathrm{m}$

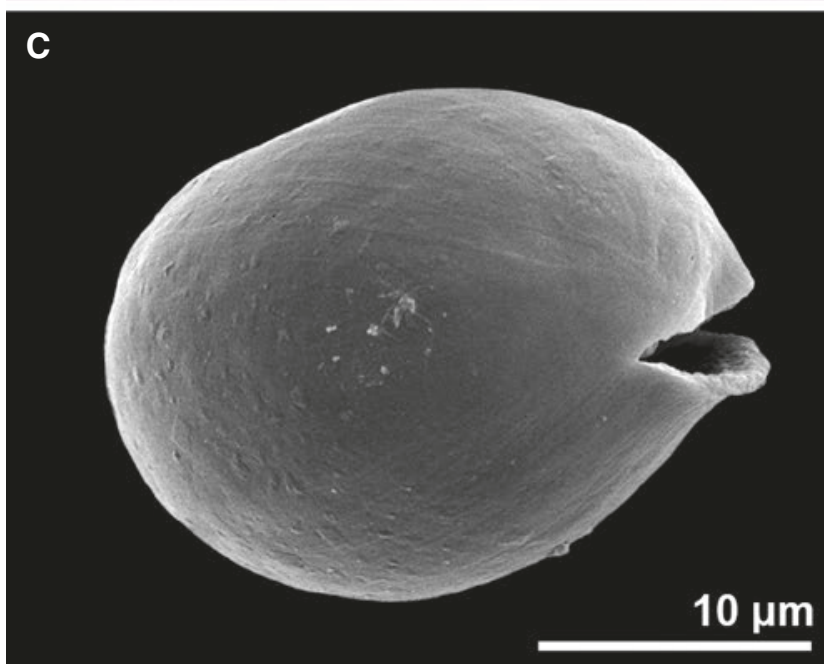

Fig. 19 Preparation effect - psilate vs. ornamented. A-C. Amorphophallus krausei, Araceae, pollen striate in hydrated condition (A), psilate after acetolysis, LM (B) and SEM (C)
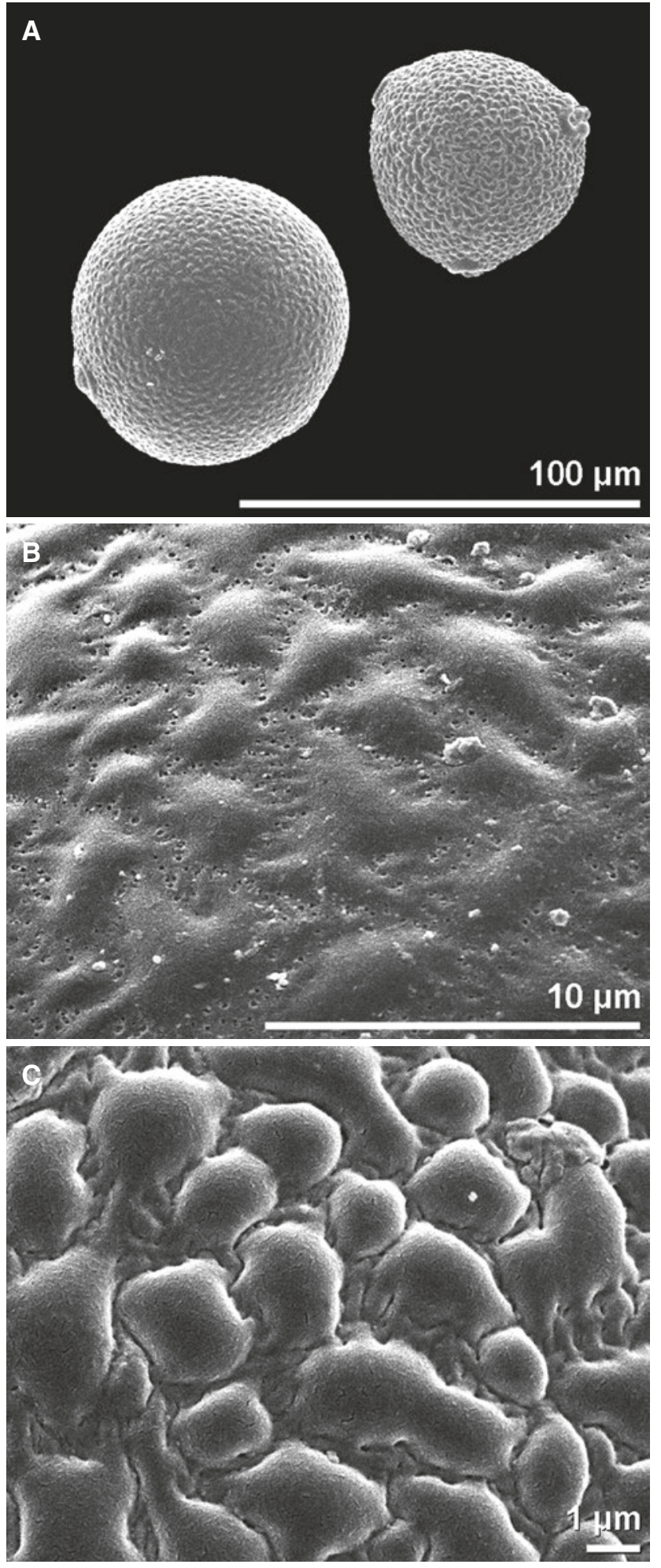

Fig. 20 Preparation effect on ornamentation. A-C. Trichosanthes anguina, Cucurbitaceae. A. Pollen at different state of hydration: fully hydrated (left), less hydrated (right). B. Hydrated pollen, surface detail, verrucate, perforate. C. Less hydrated, surface detail, areolate-fossulate 
A

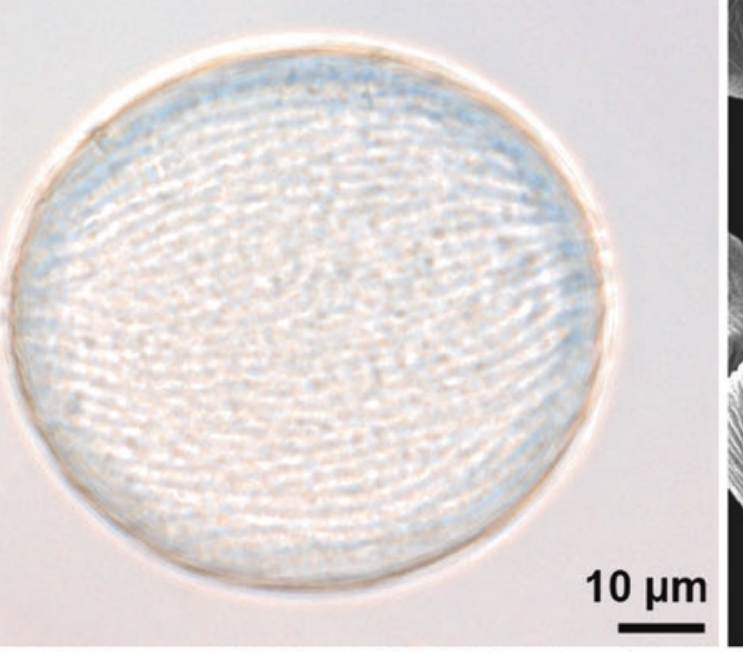

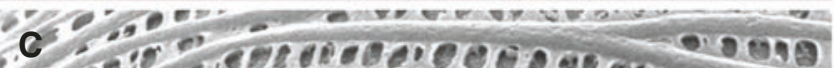

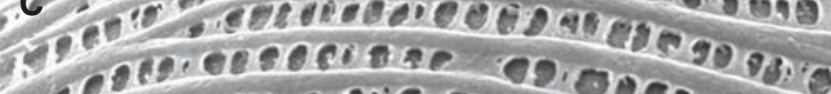

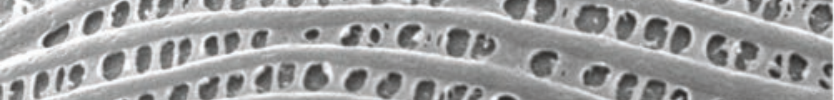
1)

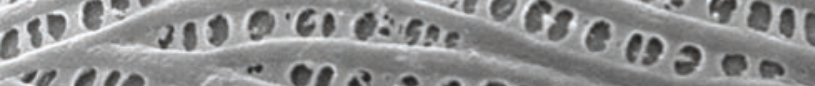

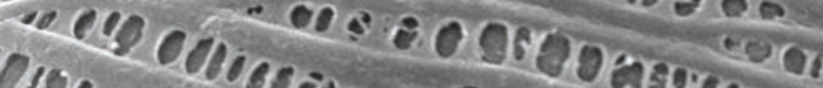

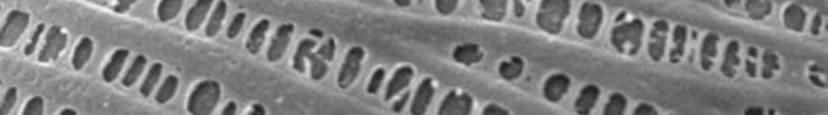

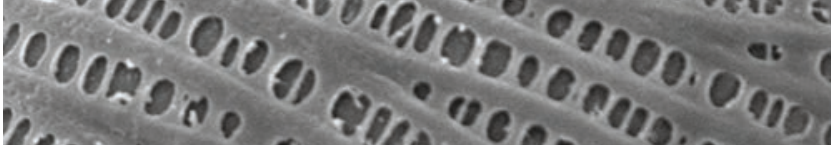

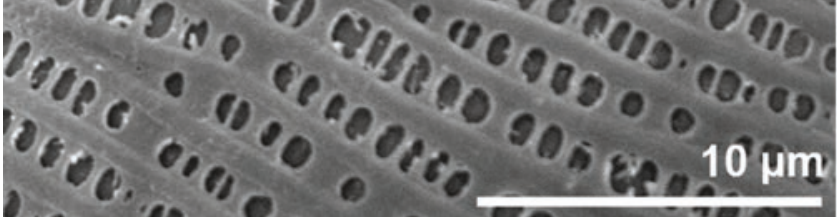

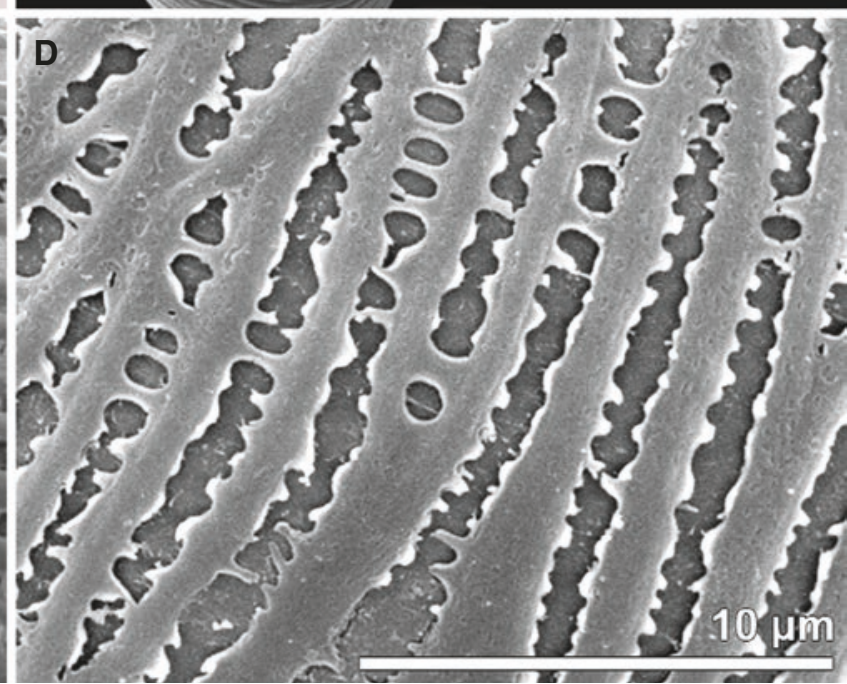

Fig. 21 Preparation effect on ornamentation. A-D. Amorphophallus longituberosus, Araceae, hydrated pollen in water with striate ornamentation, LM (A), dry pollen in SEM, striate (B), hydrated pollen in SEM, striate to reticulate (C), hydrated pollen in SEM, ornamentation striate with expanding thin surface layer (D)
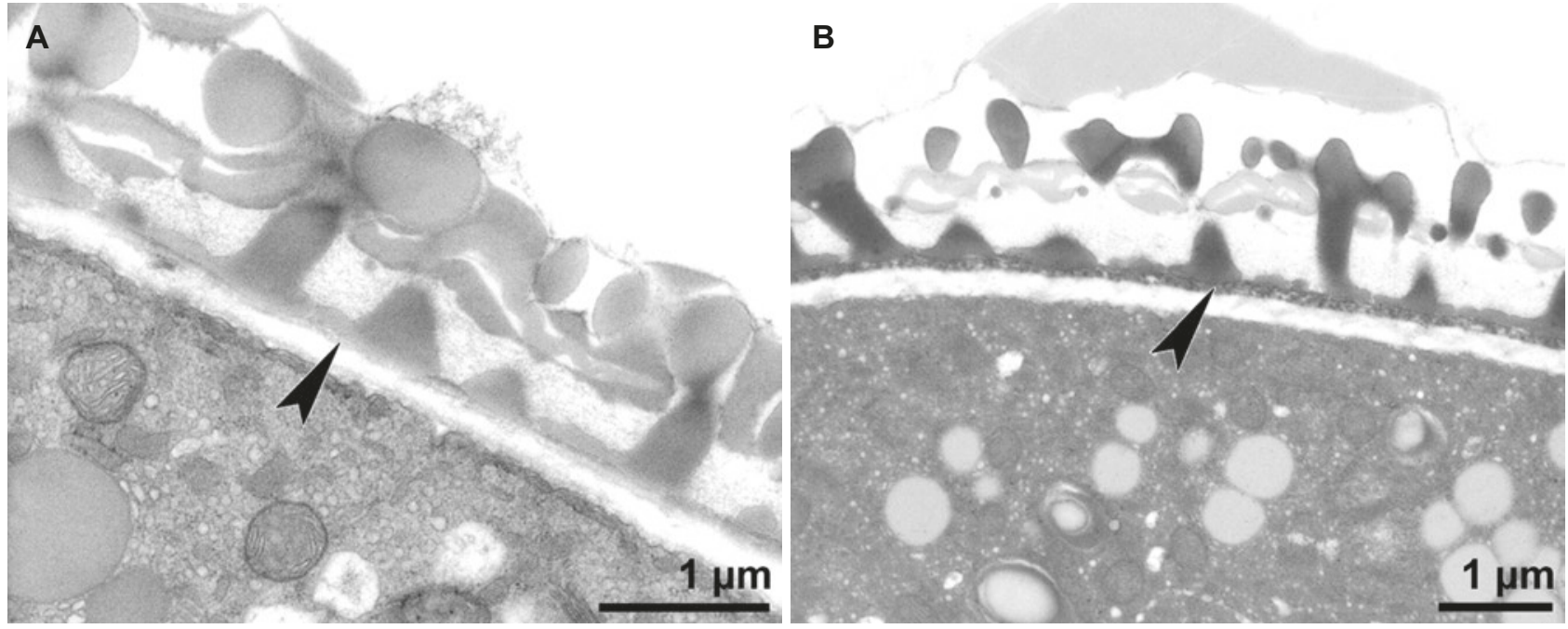

Fig. 22 Absence or presence of endexine. A-B. Thymus odoratissimus, Lamiaceae, U + Pb staining, endexine (arrowhead) not clearly visible (A), potassium permanganate staining, endexine (arrowhead) clearly visible (B) 


\section{References}

Erdtman G (1952) Polelen Morphology and Plant Taxonomy. Angiosperms. Almqvist \& Wiksell, Stockholm

Fever SM (1977) Pollen morphology and evolution in the Santalales sen. str., a parasitic order of flowering plants. Thesis, University of Massachusetts

Feuer SM, Kuijt J (1985) Fine structure of mistletoe pollen VI. Small flowered neotropical Loranthaceae. Ann Missouri Bot Gard 72: 187-212

Gabarayeva NI, Rowley JR (1994) Exine development in Nymphaea colorata (Nymphaeaceae). Nordic J Bot 14: 671-691

Grayum MH (1992) Comparative external pollen ultrastructure of the Araceae and putatively related taxa. Monogr Syst Bot Missouri Bot Garden 43: 1-167

Grímsson F, Grimm, GW, Zetter R (2018) Evolution of pollen morphology in Loranthaceae. Grana 57: 16-116

Halbritter H (2016) Pontederia cordata. In: PalDat - A palynological database. https://www.paldat.org/pub/ Pontederia_cordata/300430; [accessed 2018-08-07]

Halbritter H, Hesse M (1993) Sulcus morphology in some monocot families. Grana 32: 87-99

Harley MM (1999) Tetrad variation: its influence on pollen form and systematics in the Palmae. In: Kurmann $\mathrm{MH}$, Hemsley AR (eds) The Evolution of Plant Architecture. Royal Botanic Gardens, Kew, p. 289-304

Harley MM (2004) Triaperturate pollen in the monocotyledons: configuration and conjecture. Plant Syst Evol 247: 75-122

Hesse M, Halbritter H, Weber M (2009) Beschorneria yuccoides and Asimina triloba (L.) Dun: examples for proximal polar germinating pollen in angiosperms. Grana 48: 1151-159

Hesse M, Zetter R (2005) Ultrastructure and diversity of recent and fossil zona-aperturate pollen grains. Plant Syst Evol 255: 145-176

Huynh KL (1976) Arrangement of some monosulcate, disulcate, trisulcate, dicolpate and tricolpate pollen types in the tetrads, and some aspects of evolution in the angiosperms. In: Ferguson IK, Muller M (eds) The evolutionary significance of the exine. Academic Press, London, p. 101-124
Iversen J, Troels-Smith J (1950) Pollenmorfologiske definitioner og typer. Pollenmorphologische Definitionen und Typen. Danm Geol Unders, ser 4, 3: 1-54

Kremp GOW (1968) Morphologic Encyclopedia of Palynology. $2^{\text {nd }}$ edition, Arizona Press, Tucson

Punt W, Hoen PP, Blackmore S, Nilsson S, Le Thomas A (2007) Glossary of pollen and spore terminology. Rev Palaeobot Palynol 143: 1-81

Richard LC (1817) De Orchideis Europaeis annotationes, praesertim ad genera dilucidanda spectantes. Belin, Paris

Schols P, Furness CA, Merckx V, Wilkin P, Smets E (2005) Comparative pollen development in Dioscoreales. Int J Plant Sci 166: 909-924

Teppner H (2007) Notes on terminology for Mimosaceae polyads, especially in Calliandra. Phyton 46(2): 231236

Traverse A (2007) Paleopalynology. 2nd ed, Springer, Dordrecht

Ulrich S, Hesse M, Bröderbaver D, Bogner J, Weber $M$, Halbritter H (2013) Calla palustris (Araceae): New insights with special regard to its controversial systematic position and to closely related genera. Taxon 62: $701-712$

Ulrich S, Hesse M, Weber $M$, Halbritter H (2017) Amorphophallus: New insights into pollen morphology and the chemical nature of the pollen wall. Grana 56: $1-36$

Wagenitz $G$ (2003) Wörterbuch der Botanik. $-2^{\text {nd }}$ edition, Spektrum, Heidelberg

Walker JW (1971) Pollen morphology, phytogeography, and phylogeny of the Annonaceae. Contributions from the Gray Herbarium 202: 1-131

Weber M, Halbritter H, Hesse M (1999) The basic pollen wall types in Araceae. Int J Plant Sci 160: 415-423

Weber M, Ulrich S (2010) The endexine: a frequently overlooked pollen wall layer and a simple method for detection. Grana 49: 83-90

Wettstein R (1907) Handbuch der systematischen Botanik 2(2/1): 161-394

Zetter R, Ferguson DK (2001) Trapaceae pollen in the Cenozoic. Acta Palaeobot 41: 321-339

Open Access This chapter is licensed under the terms of the Creative Commons Attribution 4.0 International License (http://creativecommons.org/licenses/by/4.0/), which permits use, sharing, adaptation, distribution and reproduction in any medium or format, as long as you give appropriate credit to the original author(s) and the source, provide a link to the Creative Commons license and indicate if changes were made.

The images or other third party material in this chapter are included in the chapter's Creative Commons license, unless indicated otherwise in a credit line to the material. If material is not included in the chapter's Creative Commons license and your intended use is not permitted by statutory regulation or exceeds the permitted use, you will need to obtain permission directly from the copyright holder. 